\title{
Sulodexide for Diabetic-Induced Disabilities: A Systematic Review and Meta-Analysis
}

\author{
Angelo A. Bignamini (D) - Ahmed Chebil • Giovanni Gambaro • \\ Jiří Matuška
}

Received: December 7, 2020 / Accepted: January 6, 2021 / Published online: January 27, 2021

(C) The Author(s) 2021

\begin{abstract}
Introduction: Micro- and macrovascular complications of diabetes are leading morbidities in the world population. They are responsible not only for increased mortality but also severe disabilities, which jeopardize quality of life (e.g., blindness, walking limitations, and renal failure requiring dialysis). The new antidiabetic agents (e.g., glucagon-like peptide 1 receptor agonists and sodium-glucose cotransporter inhibitors) are increasingly recognized as breakthrough agents in the treatment of diabetes and prevention of diabetic complications.
\end{abstract}

Supplementary Information The online version contains supplementary material available at https:// doi.org/10.1007/s12325-021-01620-1.

A. A. Bignamini $(\bowtie)$

School of Specialisation in Hospital Pharmacy, Department of Pharmaceutical Sciences, University of Milan, Milan, Italy

e-mail: angelo@aabignamini.it

A. Chebil

Department B of Ophthalmology, Hedi Rais Institute of Ophthalmology, Faculty of Medicine of Tunis, University of El Manar, Tunis, Tunisia

G. Gambaro

Division of Nephrology and Dialysis, Ospedale

Maggiore, University of Verona, Verona, Italy

J. Matuška

MATMED S.R.O., Private Angiology Facility,

Hodonin, Czech Republic
However, drugs effective in preventing and treating diabetic disabilities are still needed and sulodexide could be one of those able to address the unmet clinical needs of the new antidiabetic agents.

Methods: We searched MEDLINE, EMBASE, the Cochrane Central Register of Controlled Trials, and the World Health Organization (WHO) International Clinical Trials Registry Platform Search Portal. We also manually searched potentially relevant journals, conference proceedings, and journal supplements. Any study monitoring any effect of sulodexide in subjects with diabetes, in relation to renal, vascular, and ocular complication, was considered. Treatment effects were estimated using standardized mean differences (SMDs), mean differences (MDs), and risk ratios (RRs), as appropriate. We calculated 95\% confidence interval (CIs) and heterogeneity $\left(Q\right.$, tau, and $\left.I^{2}\right)$.

Results: The search found 45 studies with 2817 participants (mean age 57 years; $63 \%$ male). The 26 randomized controlled studies included 2074 participants (mean age 58.8 years; 66\% male). Sulodexide reduced the impact of diabetic retinopathy; increased the pain-free and maximal walking distance in peripheral arterial disease; accelerated the healing of diabetes-associated trophic ulcers; and decreased the rate of albumin excretion in subjects with nephropathy. The risk of adverse events (AEs) was not different between sulodexide and controls. 
Conclusion: Sulodexide has a beneficial effect on the ocular, peripheral arterial disease, trophic ulcers, and renal complications of diabetes without increasing the risk of AEs.

Keywords: Claudication;

Diabetes complications; Diabetes-associated trophic ulcers; Efficacy; Meta-analysis; Nephropathy; Peripheral arterial disease; Retinopathy; Sulodexide

\section{Key Summary Points}

Why carry out this study?

Diabetic micro- and macrovascular complications lead to increased morbidity and mortality, and drugs effective in preventing and treating these complications are needed.

Sulodexide is a glycosaminoglycan that may be useful in the prevention and management of diabetic disabilities, including renal, ocular, and peripheral vascular complications.

The aim of this systematic review and meta-analysis was to examine the effects of sulodexide for prevention and/or management of diabetic micro- and macrovascular complications.

\section{What was learned from the study?}

Sulodexide improved symptoms in patients with diabetic retinopathy, peripheral arterial disease, trophic ulcers, and diabetic nephropathy without increasing the risk of adverse events versus controls.

Sulodexide may provide therapeutic benefits to patients with diabetes, enabling effective management and/or prevention of diabetic complications in clinical practice.

\section{DIGITAL FEATURES}

This article is published with digital features, including a summary slide, to facilitate understanding of the article. To view digital features for this article go to https://doi.org/10.6084/ m9.figshare.13526489.

\section{INTRODUCTION}

People with diabetes can suffer with a wide range of syndromes, from acute life-threatening conditions to long-term severe diabetic-induced disabilities affecting the central and peripheral circulation as well as the ocular and peripheral nervous system [1]. It is estimated that diabetes prevalence is increasing across the world $[2,3]$, and, in spite of the currently extended and aggressive management of hyperglycemia, so are the associated disabilities.

Micro- and macrovascular complications of diabetes are leading morbidities worldwide [4]. They are not only responsible for increased mortality, mainly cardiovascular, but also for severe disabilities, which jeopardize quality of life, including blindness, movement limitations (due to claudication and diabetic foot), and renal failure requiring dialysis.

Strict control of glycemia and of blood pressure, especially with angiotensin-converting enzyme (ACE) inhibitors or angiotensin receptor blockers (ARBs), and intensified multifactorial treatment are considered a first step to reduce the risk of complications, including stroke [5], peripheral arterial disease (PAD) [6], retinopathy [7], and nephropathy [8].

Since 2005, when glucagon-like peptide 1 receptor agonists (GLP-1RAs), 2006, when dipeptidyl peptidase 4 (DPP4) inhibitors started to be used, up to recent days with the use of sodium-glucose cotransporter 2 (SGLT2) inhibitors, the therapeutic armamentarium for the treatment of diabetes has been considerably enriched. These new agents have been primarily designed to improve the glycemic control of diabetes, but for some of them, particularly GLP-1RAs and SGLT2 inhibitors, the clinical effect on cardiovascular mortality and on diabetic nephropathy goes well beyond their effect 
on metabolic control. This suggests that these drugs may also work on targets unrelated to glucose metabolism to deploy their favorable effects on diabetic complications. However, it is not known how these new drugs affect diabetic retinopathy, PAD, and the diabetic foot, while concerns were raised about the risk of worsening PAD by the SGLT2 inhibitor canagliflozin [9]. Thus, drugs effective in preventing and treating these complications and in general diabetic disabilities are still needed.

Since the presentation of the Steno hypothesis on the pathogenesis of diabetic complications [10], the endothelial glycocalyx began being considered a key player in the course of diabetes and its complication [11]. The protective effect of sulodexide on the glycocalyx [12-17] made it well suited to prevent endothelial glycocalyx degradation or to restore it in diabetes.

Sulodexide is a glycosaminoglycan that comprises two fractions: fast-moving heparin fraction (80\%) that has affinity for antithrombin III, plus a dermatan sulfate fraction (20\%) that has affinity for heparin cofactor II [18]. Experimental investigations showed a favorable effect of sulodexide in diabetic rats, not only reducing proteinuria $[19,20]$ but also protecting the endothelial morphology and function [21-23]. This could be associated with a protective and regenerating action on the glycocalyx in experimental studies [24-27] and in humans [28]. The fine mechanisms involve an anti-inflammatory [29-31], anti-proteolytic $[32,33]$, and antioxidant effect [25, 34, 35], including interference with metabolic and nonmetabolic stress [36]. Inhibition of heparanase $[37,38]$ is likely to contribute to the endothelial protection, as well as the reduction of advanced glycation end products-related signaling [39], the prevention of the progression of vascular wall stiffness [40], the inhibition of the vascular endothelial growth factor synthesis [41], and the favorable effects on endothelial nitric oxide $[42,43]$. Sulodexide does not target glucose metabolism and does not affect the glycemic control; nevertheless, a large trial performed before the current guidelines for the management of myocardial infarction went into effect, which included $10 \%$ of patients with diabetes, reported a decreased risk for the composite of reinfarction and cardiovascular mortality [44].

Thus, sulodexide could be one of the drugs effective in preventing and treating diabetic complications and in general diabetic disabilities, and able to address the unmet clinical needs of the new antidiabetic agents.

\section{Objectives}

The aim of this systematic review and the associated meta-analyses was to gather and summarize the available information on the effect of sulodexide to prevent and/or manage diabetic disabilities (i.e., the renal, ocular, and peripheral vascular complications).

\section{METHODS}

\section{Criteria for Considering Studies for This Review}

We included all comparative and non-comparative trials assessing the efficacy of sulodexide in patients with type 1 or type 2 diabetes, in relation to the relevant complications affecting the eye (diabetic retinopathy), the peripheral circulation (lower limb ischemia with or without ulcers and claudication), and the kidney (micro- and macroalbuminuria). We excluded studies that did not meet the above criteria as well as studies that could not be retrieved in extenso. We imposed no limitation to language, journal, or date of publication.

\section{Types of Patients}

Patients included consenting men and women over 18 years of age with any of the indicated complications due to type 1 or type 2 diabetes; we also included the only study performed with sulodexide in adolescents (age 13-17 years) with diabetic nephropathy [45]. 


\section{Types of Interventions}

All studies with at least one arm that was treated orally with sulodexide with or without a run-in period with intramuscular/intravenous injections, at any dosage, and for any duration of treatment were included.

\section{Types of Outcome Measures}

Studies that assessed any of the following outcome measures were included:

1. Ocular complications: diabetic retinopathy; macular edema

2. Vascular complications: in patients with claudication, pain-free distance walked and/or maximal distance walked; in patients with trophic ulcers, proportion healed in 2 months and/or time to complete re-epithelization

3. Renal complications: changes in urinary albumin excretion

4. Adverse events (AEs): number of patients who reported AEs, regardless of whether indicated as potentially correlated with the treatment

\section{Search Methods}

The searches were conducted in the following electronic databases: MEDLINE, EMBASE, the Cochrane Central Register of Controlled Trials, and the World Health Organization (WHO) International Clinical Trials Registry Platform Search Portal. To favor sensitivity, the search terms were "sulodexide", "glycosaminoglycan OR glucosaminoglycan", "diabetes", "clinical study OR clinical trial". The reference lists of articles retrieved by electronic searches were also reviewed for additional citations; other potentially relevant journals, conference proceedings, and journal supplements were handsearched. The electronic search included papers published up to 31 December 2019; the complete search was concluded on 29 February 2020 .

\section{Data Collection and Analysis}

The authors independently assessed the eligibility of studies identified by the searches; disagreements were resolved by consensus.

\section{Data Extraction and Management}

One author (AAB) extracted data from the studies; the other authors (AC for ocular complications, GG for renal complications, and JM for vascular complications) independently checked the extracted data. Possible discrepancies were reconciled by consensus. Collected information included characteristics of study participants, characteristics of intervention, and control groups (where applicable), and outcome characteristics of every group of participants.

\section{Assessment of Risk of Bias in Included Studies}

The controlled studies were assessed independently by each author for bias. In particular, the risks of bias arising from the randomization process, due to deviations from the intended interventions, due to missing outcome data, the risk of bias in measurement of the outcome, and in selection of the reported results were assessed. Once this information was gathered, review authors classified each study into one of three levels of risk of bias (low, some concerns, or high) based on the criteria specified in the Cochrane Handbook for Systematic Reviews of Interventions [46], with the aid of the RoB 2 tool [47]. Possible discrepancies were resolved by consensus.

\section{Measures of Treatment Effect}

The effects of treatment were estimated using the meta package [48] in $\mathrm{R}$ [49]. Continuous variables were examined by meta-analysis of continuous outcome data (metacont function); dichotomous variables were examined by metaanalysis of binary outcome data (metabin). Results were reported with the relevant 95\% confidence intervals (CIs). When the change of 
continuous variables at study end was not reported, we used the final measurements, which in a randomized trial in theory estimates the same quantity as the comparison of changes from baseline; when needed, the change during trial was calculated with the usual procedures to estimate the mean change [50] or the mean standardized change [51]. When data were reported as median with interquartile range, we estimated the mean and standard deviation as usual [52]. All analyses were performed using the random effects model unless specified otherwise. Heterogeneity was estimated in each analysis since high heterogeneity suggests taking the results with care or considering additional confounding factors.

In some cases the data was transformed to maintain a homogenous interpretation of the outcomes (e.g., in a study that reported the outcome as proportion of success, the data was transformed to proportion of failure); in studies that reported the outcome as percentage of baseline value with asymmetric CI, the $\log$ (percentage of baseline value) with standard deviation was estimated.

\section{Compliance with Ethics Guidelines}

This article is based on previously conducted studies and does not contain any studies with human participants or animals performed by any of the authors.

\section{RESULTS}

\section{Results of the Search}

Figure 1 provides a summary of the literature search results and screening process. Among the 11 reports that could not be retrieved in extenso, nine were relevant to randomized controlled trials (RCTs) including 274 patients treated with sulodexide [53-61], but the details given in the abstracts were insufficient to reliably estimate the outcome.

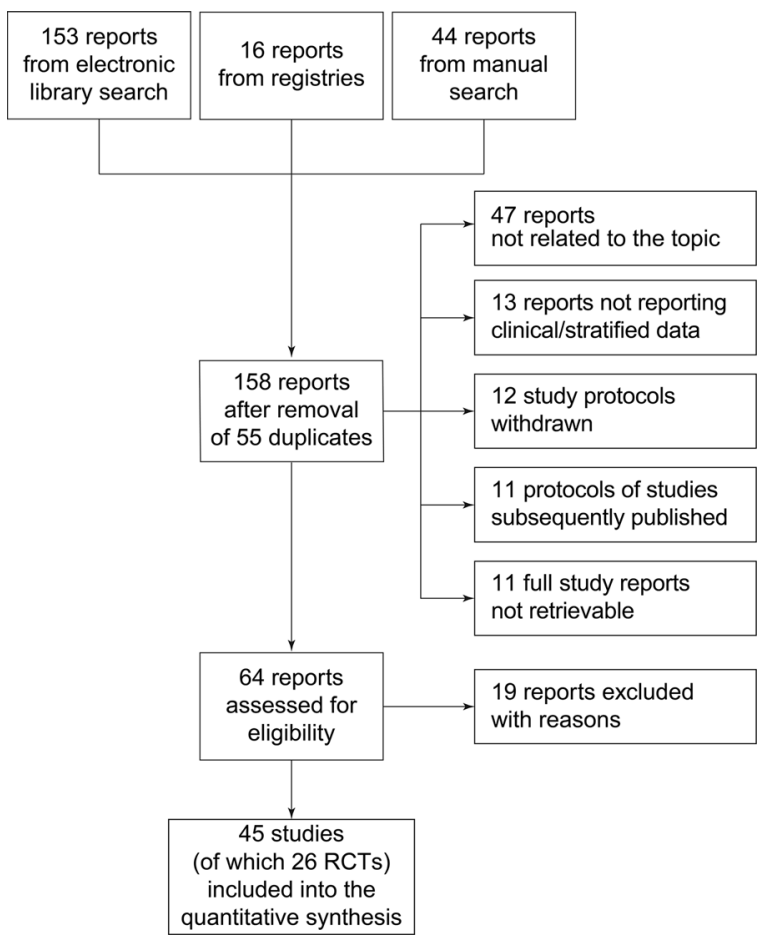

Fig. 1 Summary of the literature search and screening process

\section{Included Studies}

We identified 45 studies that could provide information on the effect of sulodexide in the prevention and/or management of the complications of diabetes, four on ocular complications [62-65], seven on PAD or diabetesassociated trophic ulcers [66-72], and 34 on diabetic nephropathy [45, 73-105]. Data were retrieved from the original published tables or graphs. Additional information was obtained from the original clinical study reports for three studies $[69,89,97]$.

Overall, the studies considered in this review included 2817 patients exposed to sulodexide; $63 \%$ were male, mean age was 56.8 years, and $85 \%$ were affected by type 2 diabetes. The randomized controlled trials included 2074 patients receiving sulodexide, of whom $66 \%$ male, mean age was 58.8 years, and $91 \%$ had type 2 diabetes. Details on the monitored sample are reported in the supplementary material (Supplementary Tables S1, S2, and S3). 


\section{Risk of Bias in Included Studies}

The risk of bias was analytically estimated for the 25 comparative studies and is reported in the supplementary material (Supplementary Table S4); the 20 non-comparative studies should in principle be considered at high risk of bias. Supplementary Table S5 and Supplementary Fig. S1 summarize the risk of bias of the considered studies. Overall, the two main sources of concern were the randomization procedures and the risk of selection of the reported results. The first was mostly associated with the trials using a run-in period with parenteral administration, which were frequently openlabel trials, or with the absence of a true randomization procedure. Randomization was not necessarily associated with blinding. Blinding, with appropriate masking when needed, was specifically indicated in 11 studies $[64,68-70,75,80,89,92,97,99,102]$. Another 13 studies were explicitly defined or implicitly detected as open-label [63, 71, 72, 74, 90, 91, 94-96, 98, 100, 101, 104]. The risk of selection of the reported results was due in some cases to the open-label design, but mostly to the absence of sufficient details on the protocol, so that it was impossible to understand whether the data had been analyzed in accordance with a prespecified analysis plan that was finalized before unblinded outcome data were available for analysis. Overall, $24 \%$ of studies were at low risk of bias, $40 \%$ generated some concern for bias, and $36 \%$ were at high risks of bias (Fig. 2). Studies rated at low risk or with at most some concern were classified as high quality; studies rated at high risk were classified as low quality.

\section{Excluded Studies}

Nineteen out of the 64 studies assessed for eligibility were excluded because they contained no quantitative data that was extractable [106-114], did not report any of the chosen endpoints [28, 115-119], their data were not stratified by pathology or treatment $[120,121]$, data were reported without variance [122], or control data were only historical [123].

\section{Effects of Interventions}

The effects of intervention were included into four major groups: signs of diabetic retinopathy, signs of PAD or of diabetes-associated trophic ulcers, signs of diabetic nephropathy, and AEs.

We found an extreme heterogeneity in outcome reporting. Signs of retinopathy were monitored as change in hard exudate severity [64], hard exudate and hemorrhage frequency [62], incidence of intraocular hemorrhage after panretinal laser coagulation [63], and rate of recurrence of retinal vein thrombosis [65]. Vascular complications were monitored using more homogeneous endpoints: pain-free walking distance $[67,69,70]$ and maximal walking distance $[66,67,69,70]$ in PAD, and rate of and time to re-epithelization for diabetes-associated trophic ulcers $[68,71,72]$.

The studies on diabetic nephropathy described essentially the same phenomenon: change

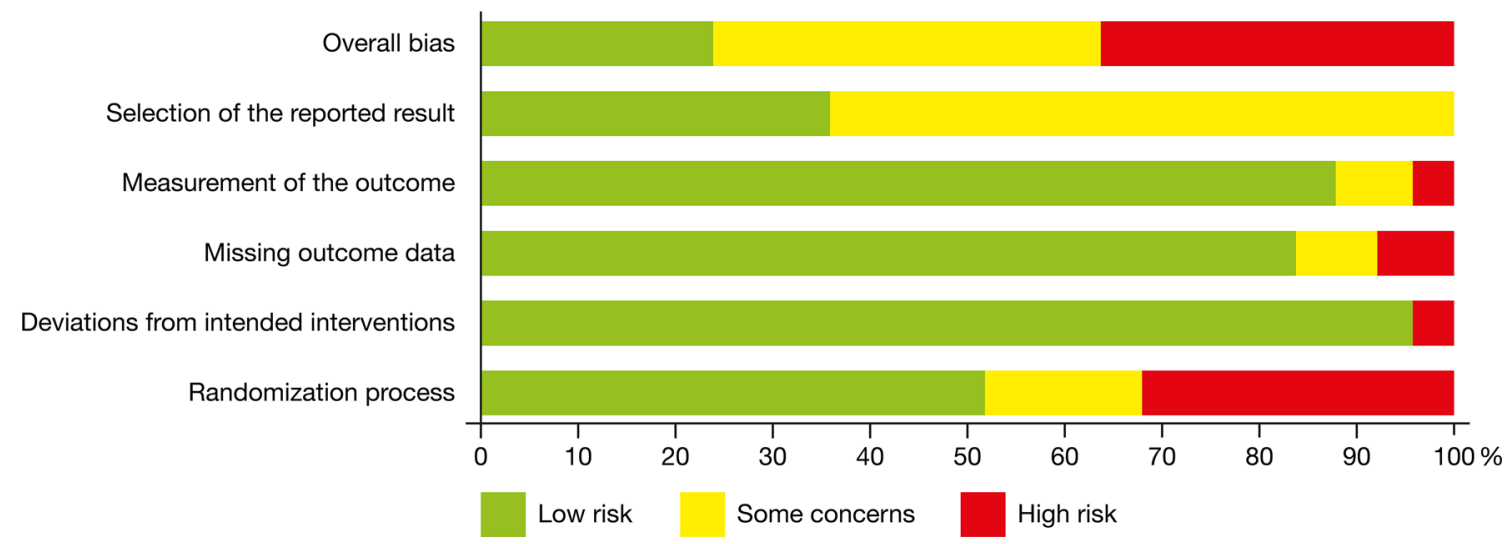

Fig. 2 Overall evaluation of the risk of bias in the comparative studies included in the quantitative synthesis 
in albuminuria, but measured and reported with different techniques, namely arithmetic mean (reported or derived [52]) as micrograms per minute or milligrams per day or milligrams per $24 \mathrm{~h}$ or micrograms per milligram creatinine $[45,73-78,80-83,85-88,91,94,96,98$, 101-103, 105], geometric mean [79, 84, 89, $95,100]$, geometric mean of percentage change $[90,93,104]$, rate of change in micrograms per milligram per year [99], or therapeutic success defined in different ways [92, 97]. Geometric means, reported with the asymmetric 95\% CI, had to be logarithmically transformed to estimate the symmetric standard deviation. When outcome was reported as proportion of success, we had to transform the result into proportion of failure, to maintain the same direction of the difference as for the other studies.

\section{Signs of Diabetic Retinopathy}

Ocular complications of diabetes were monitored in two non-comparative and two comparative studies (Supplementary Table S1). Each study examined different conditions, so that a summary could not be compiled.

A register monitored the rate of recurrence of retinal vein thrombosis in the first year after a first episode, in four groups of patients nonrandomly selected, largely underpowered to detect an effect of sulodexide [65]. The other open study monitored the course of hard exudates, retinal hemorrhages, and intraretinal microvascular abnormalities (IRMA) in 4 months in a small cohort (30 patients). The authors reported a significant decrease of hard exudates, retinal hemorrhages, and IRMA in 4 months [62]. A comparative non-blinded study examined the incidence of intraocular hemorrhages in 4 months after panretinal laser coagulation, incidence that was too low (less than $10 \%$ total) to allow a meaningful comparison [63]. Finally, the last study, performed according to a proper design and on a sufficiently large sample of affected eyes, reported a significant decrease of the severity of macular hard exudates in the year of treatment with sulodexide versus controls.

The use of sulodexide produced a decrease in macular hard exudates in patients with mild-tomoderate non-proliferative diabetic retinopathy. Treated patients experienced an odds ratio of improving which was 2.79 times (95\% CI 1.16-6.74) that of controls $(p=0.023)$ [64].

Overall, there is enough evidence to consider that the therapy with sulodexide over 4-12 months can reduce the severity of hard exudates in non-proliferative diabetic retinopathy. It is possible that sulodexide may decrease the risk of retinal hemorrhages and IRMA in the same patients. There is to date no evidence of an effect on the risk of intraocular hemorrhages after laser coagulation.

\section{Signs of Peripheral Vascular Complications}

The effect of sulodexide on the peripheral vascular complications of diabetes was monitored in two non-comparative and six comparative trials (Supplementary Table S2), which examined PAD (five studies), diabetes-associated trophic ulcers (two studies), and the diabetic foot (one study).

Peripheral Arterial Disease The endpoints monitored in the relevant studies were the pain-free walking distance and the maximal walking distance. Treatment was performed with a run-in period of $2-3$ weeks with one intramuscular injection daily of 600 lipase-releasing unit (LRU; except in one study), followed by a variable period of oral treatment with 250 or 500 LRU twice daily, for a total observation period of 3 weeks to 6 months (mean 22 weeks) in 119 patients. The control arm included 64 patients given placebo according to the double-blind design, and 12 patients monitored under the standard of care. The procedure to measure pain-free and maximal walking distance has been standardized for a long time, although the studies failed to report the details of such procedures; we nevertheless considered it reasonable to use the fixed effect model. The results were normally reported as mean change from baseline; where reported as mean value before and after treatment, we estimated the mean change with the usual procedures [50].

Pain-Free Walking Distance The three independent estimates of the treatment effect 


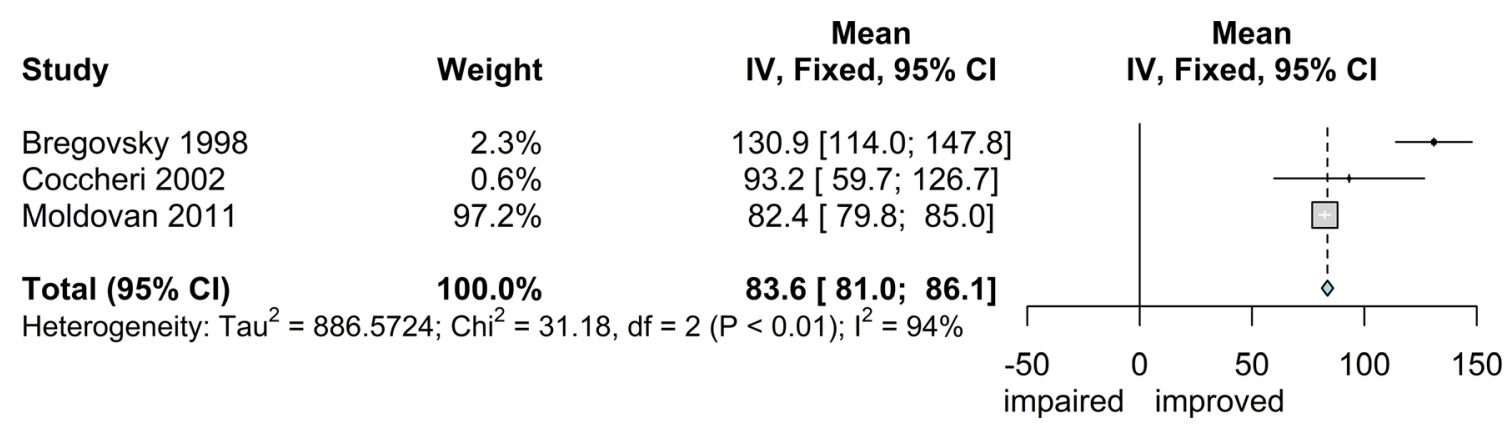

Fig. 3 Forest plot of overall mean from studies reporting a single mean. Sulodexide in diabetic peripheral arterial disease; mean increase in pain-free walking distance using the inverse variance method

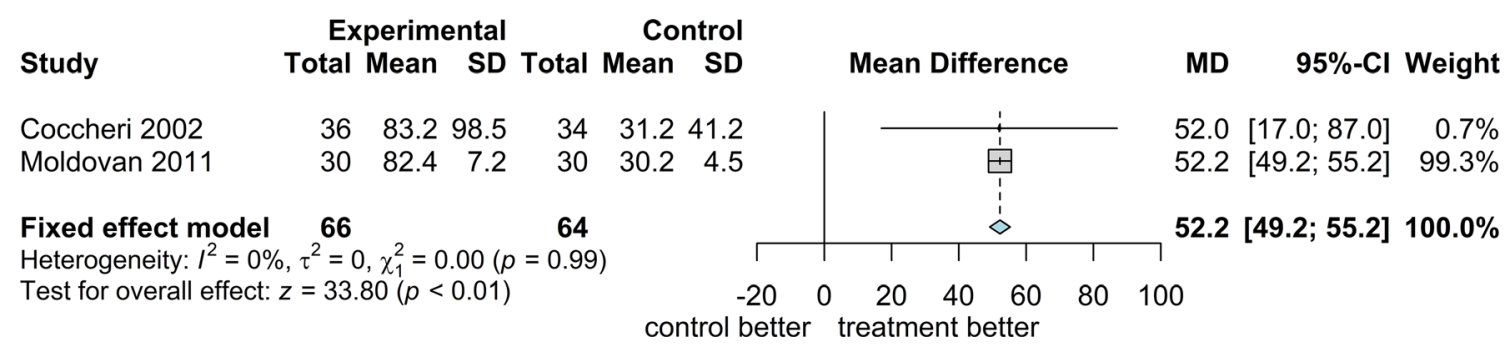

Fig. 4 Forest plot of comparison: Sulodexide versus controls in diabetic peripheral arterial disease; mean increase in painfree walking distance

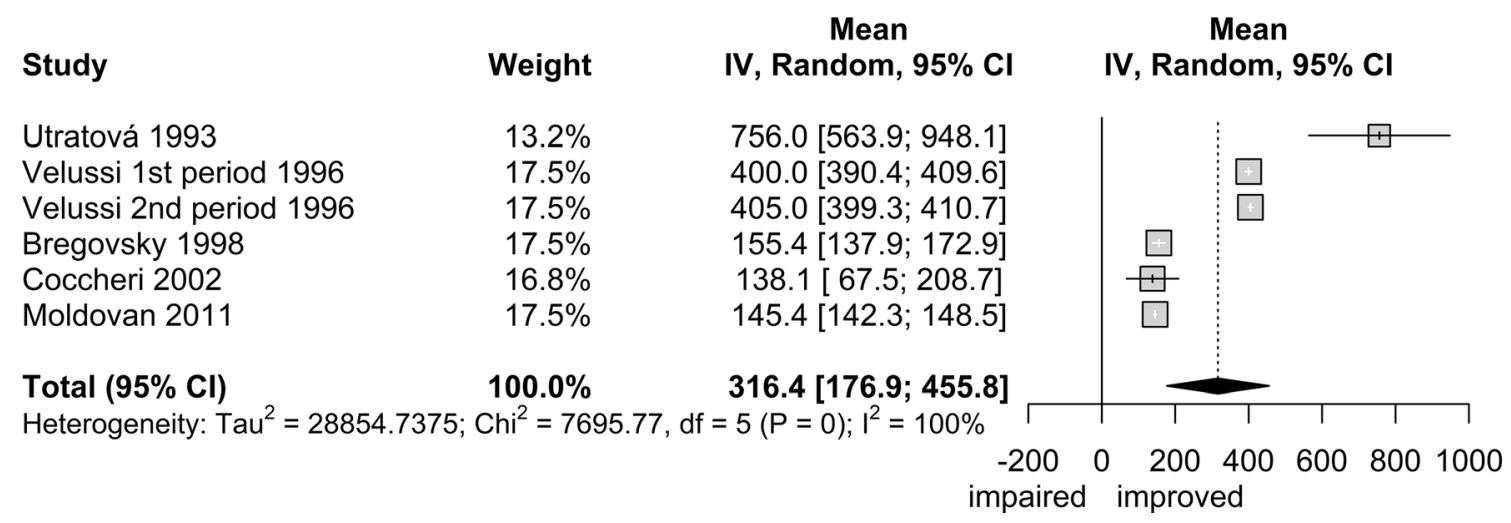

Fig. 5 Forest plot of overall mean from studies reporting a single mean. Sulodexide in diabetic peripheral arterial disease; mean increase in maximal walking distance using the inverse variance method

yielded an overall estimate of the increase of pain-free walking distance of $84 \mathrm{~m}(95 \% \mathrm{CI}$ 81-86; Fig. 3). This estimate was approximately $60 \%$ larger than the difference from the comparator (+ $52 \mathrm{~m}$; 95\% CI 49-55; $p<0.01$; Fig. 4), indicating that this variable probably presented quite a large placebo effect.
Maximal Walking Distance The six independent estimates of the treatment effect yielded an overall estimate of the increase of maximal walking distance of $316 \mathrm{~m}$ (95\% CI 177-456; Fig. 5). This estimate is approximately 2.4 times as large as the difference from the comparator (+ $131 \mathrm{~m}$; 95\% CI 127-135; $p<0.001$, Fig. 6), 


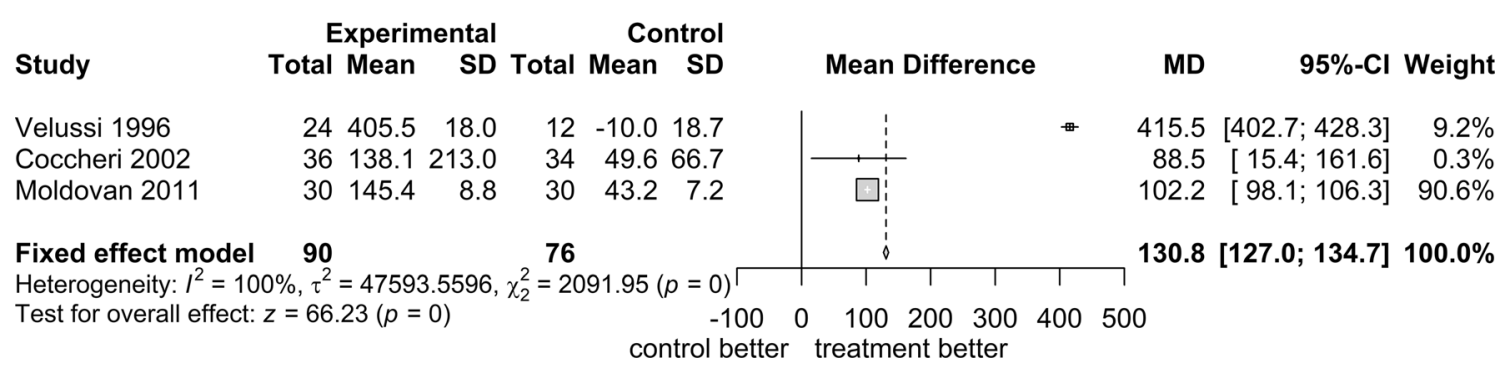

Fig. 6 Forest plot of comparison: Sulodexide versus controls in diabetic peripheral arterial disease; mean increase in maximal walking distance

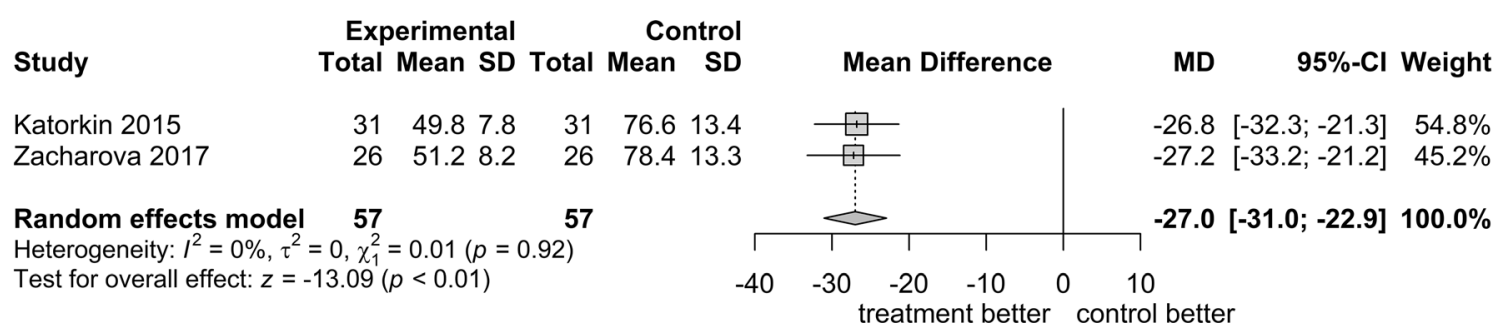

Fig. 7 Forest plot of comparison: Sulodexide versus controls in diabetes-associated trophic ulcers; mean gain in time to healing

indicating that this variable presented a large placebo effect.

Diabetes and Trophic Ulcers The endpoints monitored in the three relevant studies were the proportion of healed ulcers and the time to complete re-epithelization. Two of these studies targeted patients with CEAP class C6 chronic venous disease (chronic venous leg ulcers) and type 2 diabetes. Treatment was performed with a run-in period of 3 weeks with one intramuscular injection daily of $600 \mathrm{LRU}$, followed by 4-7 weeks of oral treatment with 250-500 LRU twice daily, for a total observation period of 7.5 weeks, in 69 patients. The control arm included six patients given placebo according to the double-blind design, and 57 patients monitored under the standard of care. One of the considered studies was designed to evaluate the course of ulcers in patients who also had diabetic foot syndrome of ischemic origin [68]; however, to avoid unnecessary clinical heterogeneity [124], the results reported in that study were not considered in the meta-analyses.
Time to Ulcer Healing The two independent estimates of the time to healing of diabetes-associated trophic ulcers indicated that subjects treated with sulodexide healed in average 27 days earlier $(95 \%$ CI $23-31 ; p<0.01)$ than the control subjects (Fig. 7). It should be noted that, despite the heterogeneity introduced if the diabetic foot study being considered, the results did not appreciably change (Supplementary Fig. S2).

Proportion of Ulcer Healing The same studies monitored the proportion of ulcer healing in 2 months of treatment. The patients treated with sulodexide experienced a chance of healing (risk ratio), which was 1.8 times (95\% CI 1.4-2.4) that of controls ( $p<0.01$; Fig. 8). In this case also, including the study on subjects with diabetic foot did not change the results nor did it substantially increase the heterogeneity (Supplementary Fig. S3).

In consideration of the complexity of chronic venous leg ulcers in subjects with diabetes, we wondered whether sulodexide could have yielded different outcomes in subjects 


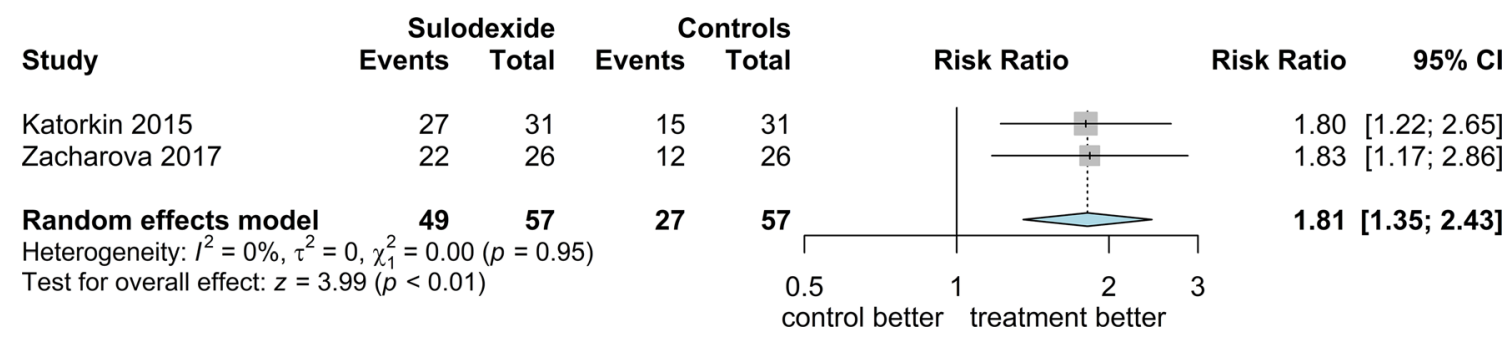

Fig. 8 Forest plot of comparison: Sulodexide versus controls in diabetes-associated trophic ulcers; healing proportion in 2 months of treatment

with diabetes and those without diabetes, also in view of the outcome of a large observational study on healing rate of ulcers treated with fourlayer bandages, where the presence of diabetes did not significantly affect the healing rate [124].

The results of the studies in patients with diabetes were compared with those of four studies monitoring the healing rate of venous lower limb ulcers in general patients, already reported in a meta-analysis [125]. The results did not differ between patients with diabetes and those without, including (Supplementary Fig. S4) and not including (Supplementary Fig. S5) the study performed in patients with diabetic foot.

\section{Signs of Diabetic Nephropathy}

Studies with sulodexide in patients with signs of diabetic nephropathy investigated the effect on albuminuria, a surrogate outcome. They are largely heterogeneous under different aspects:

(a) Some studies enrolled patients with type 1 or type 2 diabetes, or both types together without splitting the relevant outcomes.

(b) Some studies enrolled patients at specific stages of nephropathy: early (microalbuminuria, G1) or late (macroalbuminuria, G2); others enrolled patients with both levels of albuminuria without splitting the results according to the baseline category of albuminuria.

(c) Patients have been monitored under treatment with maximal dose of ACE inhibitors or ARBs, or with such treatment at dose unspecified but probably not maximal, or without such treatment, or with and without ACE inhibitors/ARB treatment without splitting the relevant outcomes, or without specifying whether the ACE inhibitors/ARB treatment was given.

(d) Treatments have been diversified by administration route (intramuscular only; intramuscular/intravenous run-in followed by oral treatment; oral treatment only); by dose (600 LRU/day parenterally only; $600 \mathrm{LRU} /$ day followed by 500-$2000 \mathrm{LRU} /$ day, $1200 \mathrm{LRU} /$ day followed by $1000 \mathrm{LRU} /$ day, 500-4000 LRU/day orally only); by duration (3 weeks to 6 months, plus two studies over 12 months [93, 103] and one planned to last up to 24 months [99] but which was not concluded) as indicated in Supplementary Table S3.

(e) Although in principle the monitored outcome was the albumin excretion rate, it was expressed as pre- and post-study data in $\mu \mathrm{g} / \mathrm{min}$ or $\log (\mu \mathrm{g} / \mathrm{min}), \mathrm{mg} / 24 \mathrm{~h}, \mathrm{mg} / \mathrm{L}$, and $\mathrm{mg} / \mathrm{g}$ creatinine; as post-study data only as percentage of baseline and $\log$ (percentage of baseline); as change during study in $\mu \mathrm{g} / \mathrm{min}, \mathrm{mg} / 24 \mathrm{~h}, \mathrm{mg} / \mathrm{L}$, percentage of baseline; rate of change in $\mu \mathrm{g} / \mathrm{min}$ per year [99] and proportion of patients reaching a pre-specified rate of albumin-tocreatinine ratio change [92, 97].

In view of such clinical heterogeneity, we performed all analyses relevant to this outcome according to the random effects model. This model, in addition, estimated the weight of the studies considering the accuracy of measurement along with the sample size, so giving some weight also to the smaller studies that would have had almost no weight with the fixed effect model. 


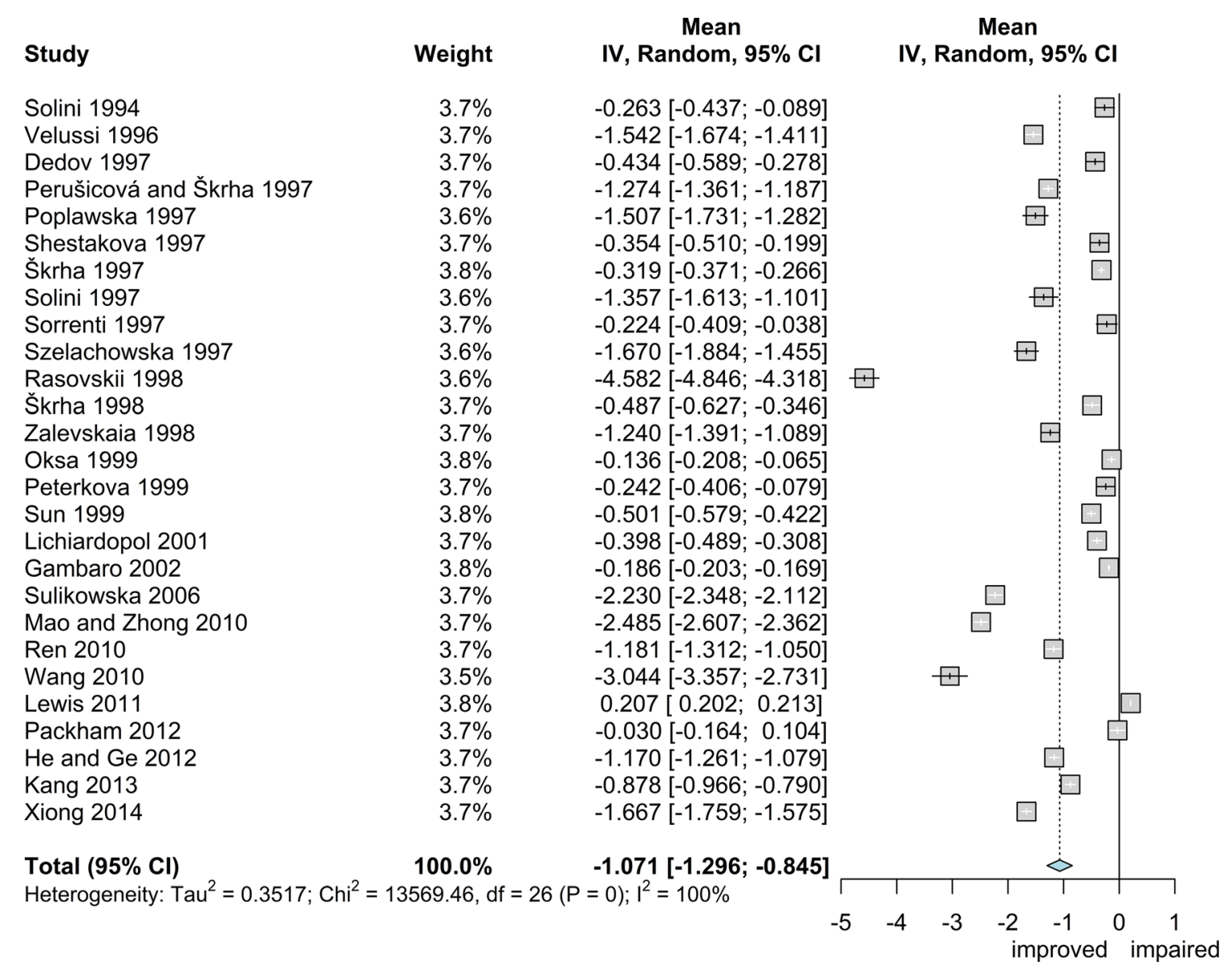

Fig. 9 Forest plot of overall mean from studies reporting a single mean. Sulodexide in renal complications of diabetes; standardized mean change of urinary albumin excretion, using the inverse variance method and the random effects model

To gather a first indication of a possible effect, we analyzed the overall mean effect from all available studies providing baseline and final information, so that the standardized mean change could be evaluated [51], or the rate of change. Overall, a significant effect of the treatment to decrease the urinary albumin excretion could be seen: the standardized effect size was estimated as -1.07 with $95 \%$ CI -1.30 to -0.85 (Fig. 9) with large heterogeneity. We then repeated the analysis including only the comparative studies. The result was not substantially different: sulodexide exhibited an effect of -1.28 (95\% CI -1.67 to $-0.90 ; p<0.01$; Fig. 10) with high heterogeneity.
Treatment Effect by Study Quality The assessment of the risk of bias in the included studies indicated that the quality of the studies-or of the study reporting, from which we estimated the risk of bias-was very variable, especially because several non-comparative studies were present that, by definition, are at high risk of bias. We therefore examined whether the quality indicated by the risk of bias could have significantly affected the summary estimate of the effect. The estimate of the effect using all available data stratified by risk of bias classified as "high" or "low", where "low" included all those studies not explicitly classified high, failed to indicate a significant difference of effect ( $p=0.26$; Fig. 11). Similarly, the analysis of the RCTs failed to indicate a 


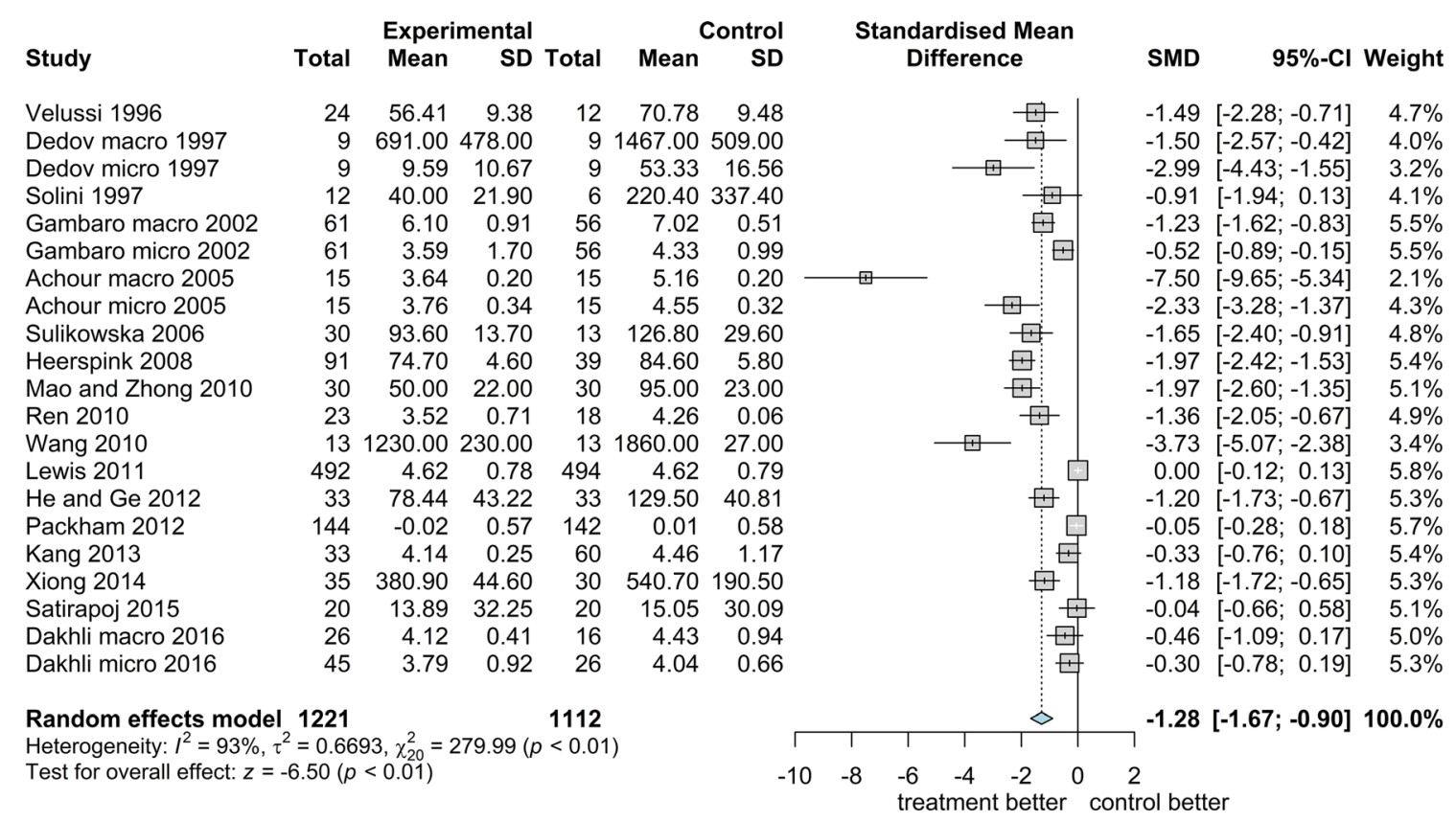

Fig. 10 Forest plot of comparison: Sulodexide versus controls in renal complications of diabetes; change in urinary albumin excretion rate, using the random effects model and the standardized mean difference. "Micro" and "macro" denote the results in the microalbuminuria and

significant impact of the risk of bias on the estimate of the summary measure of the effect $(p=0.93$; Fig. 12).

Treatment Effect by Diabetes Type The metaanalysis split by diabetes type (Fig. 13) confirmed the heterogeneity of populations, designs, treatment schedule, and settings already anticipated, showing a significant heterogeneity in the overall analysis and in each of the two subgroups (type 1 and type 2 diabetes; results from mixed-type studies were excluded). However, the effect was statistically significant in both type $1(p<0.01)$ and type 2 $(p<0.01)$ diabetes subgroups, as well as in the overall analysis $(p<0.01)$. Apparently, the effect size was somewhat greater in patients with type 1 diabetes $(-1.81 ; 95 \%$ CI -2.84 to -0.78$)$ than in patients with type 2 diabetes $(-0.99 ; 95 \% \mathrm{CI}-1.44$ to -0.54$)$. However, there was no evidence of a significant difference ( $p$ for the subgroup difference 0.15). Furthermore, four studies in patients with type 2 macroalbuminuria subgroups, respectively, where both subgroups were monitored and reported. Distribution of cases by albuminuria level is reported in Supplementary Table S3

diabetes showed no effect. Two of these studies $[74,102]$ were performed in subjects with normo- or low-micro albuminuria, in whom little changes can be expected during treatment. Two other studies $[97,99]$, which incidentally exerted an appreciable weight on the overall result, were the only ones using a different preparation of sulodexide, which might not have exerted the same pharmacodynamic action as the preparation used in all the other studies [126]. Further, both studies were performed in subjects already under maximal ACE inhibitors/ARB treatment, which might have reduced the possibility to observe an additional effect of sulodexide [126], especially in the study on patients with severe albuminuria [127], which furthermore was prematurely interrupted. Despite these large variations in comparison with all other studies, the overall estimate of the effect remained significant also in this subgroup. 


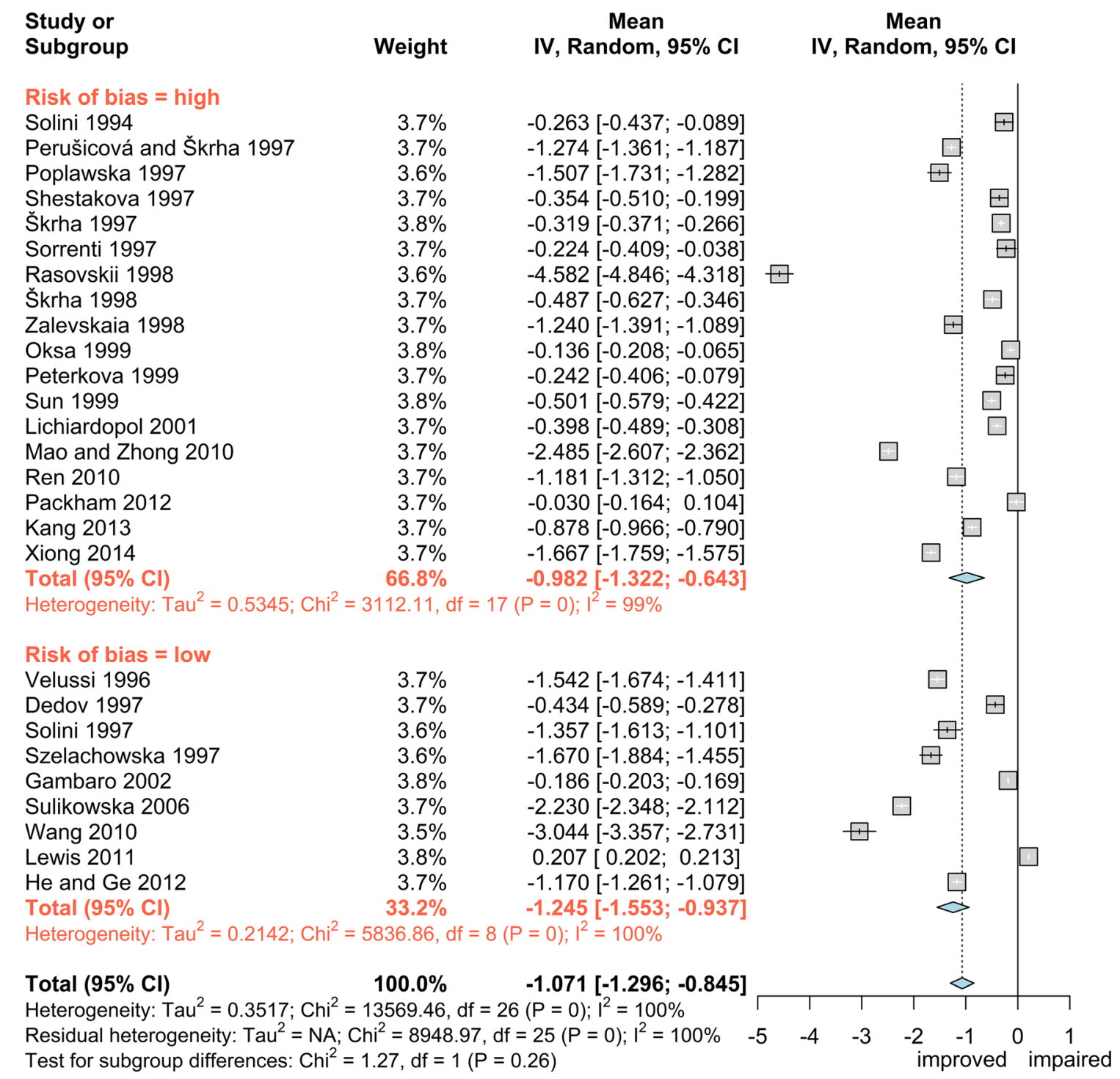

Fig. 11 Forest plot of overall mean from studies reporting a single mean. Sulodexide in renal complications of diabetes; standardized mean change of urinary albumin

Treatment Effect by Level of Albuminuria Most studies were performed in subjects with a pre-defined level of albuminuria or reported the results split by such level (Fig. 14). The effect estimated in microalbuminuria $(-1.14 ; 95 \%$ CI -1.59 to $-0.68 ; p<0.01)$ was not different ( $p=0.17$ for subgroup differences) from that estimated in macroalbuminuria $(-1.97 ; 95 \% \mathrm{CI}-3.07$ to -0.86 ; $p<0.01)$, but the heterogeneity was very large in both subgroups. excretion stratified by risk of bias, using the inverse variance method and the random effects model

Treatment Effect by Use of ACE Inhibitors/ $A R B s$ One of the issues raised to possibly explain the failure of some studies to detect an effect was that the use of sulodexide in association with maximal ACE inhibitors/ARB dose might not add an effect on its own, in addition to that of the other treatments. The meta-analysis stratifying by this variable (Fig. 15) failed to answer the question. Although there was no evidence of a significant difference in effect by ACE inhibitors/ARB use $(p=0.12$, test for 


\begin{tabular}{|c|c|c|c|c|c|c|c|c|c|c|c|}
\hline \multirow[b]{2}{*}{ Study } & \multirow[b]{2}{*}{ Total } & \multicolumn{2}{|c|}{ Experimental } & \multicolumn{3}{|r|}{ Control } & \multirow{2}{*}{\multicolumn{2}{|c|}{$\begin{array}{l}\text { Standardised Mean } \\
\text { Difference }\end{array}$}} & \multirow[b]{2}{*}{ SMD } & \multirow[b]{2}{*}{$95 \%-\mathrm{Cl}$} & \multirow[b]{2}{*}{ Weight } \\
\hline & & Mean & SD & Total & Mean & SD & & & & & \\
\hline \multicolumn{12}{|l|}{ Risk of bias $=$ low } \\
\hline Velussi 1996 & 24 & 56.41 & 9.38 & 12 & 70.78 & 9.48 & & せ & -1.49 & {$[-2.28 ;-0.71]$} & $4.7 \%$ \\
\hline Dedov macro 1997 & 9 & 691.00 & 478.00 & 91 & 1467.00 & 509.00 & & ६ & -1.50 & {$[-2.57 ;-0.42]$} & $4.0 \%$ \\
\hline Dedov micro 1997 & 9 & 9.59 & 10.67 & 9 & 53.33 & 16.56 & & 巴一 & -2.99 & {$[-4.43 ;-1.55]$} & $3.2 \%$ \\
\hline Solini 1997 & 12 & 40.00 & 21.90 & 6 & 220.40 & 337.40 & & : & -0.91 & {$[-1.94 ; 0.13]$} & $4.1 \%$ \\
\hline Gambaro macro 2002 & 61 & 6.10 & 0.91 & 56 & 7.02 & 0.51 & & $\square$ & -1.23 & {$[-1.62 ;-0.83]$} & $5.5 \%$ \\
\hline Gambaro micro 2002 & 61 & 3.59 & 1.70 & 56 & 4.33 & 0.99 & & 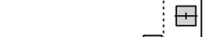 & -0.52 & {$[-0.89 ;-0.15]$} & $5.5 \%$ \\
\hline Sulikowska 2006 & 30 & 93.60 & 13.70 & 13 & 126.80 & 29.60 & & 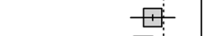 & -1.65 & {$[-2.40 ;-0.91]$} & $4.8 \%$ \\
\hline Heerspink 2008 & 91 & 74.70 & 4.60 & 39 & 84.60 & 5.80 & & 7 & -1.97 & {$[-2.42 ;-1.53]$} & $5.4 \%$ \\
\hline Wang 2010 & 13 & 1230.00 & 230.00 & 131 & 1860.00 & 27.00 & & 曰 & -3.73 & {$[-5.07 ;-2.38]$} & $3.4 \%$ \\
\hline Lewis 2011 & 492 & 4.62 & 0.78 & 494 & 4.62 & 0.79 & & & 0.00 & {$[-0.12 ; 0.13]$} & $5.8 \%$ \\
\hline $\mathrm{He}$ and $\mathrm{Ge} 2012$ & 33 & 78.44 & 43.22 & 33 & 129.50 & 40.81 & & 廿 & -1.20 & {$[-1.73 ;-0.67]$} & $5.3 \%$ \\
\hline Xiong 2014 & 35 & 380.90 & 44.60 & 30 & 540.70 & 190.50 & & ! & -1.18 & {$[-1.72 ;-0.65]$} & $5.3 \%$ \\
\hline Satirapoj 2015 & 20 & 13.89 & 32.25 & 20 & 15.05 & 30.09 & & & -0.04 & {$[-0.66 ; 0.58]$} & $5.1 \%$ \\
\hline \multicolumn{12}{|c|}{$\begin{array}{l}\text { Heterogeneity: } l^{2}=93 \%, \tau^{2}=0.7973, \chi_{12}^{2}=182.36(p<0.01) \\
\text { Test for effect in subgroup: } z=-4.83(p<0.01)\end{array}$} \\
\hline \multicolumn{12}{|l|}{ Risk of bias = high } \\
\hline Achour macro 2005 & 15 & 3.64 & 0.20 & 15 & 5.16 & 0.20 & 世 & & -7.50 & {$[-9.65 ;-5.34]$} & $2.1 \%$ \\
\hline Achour micro 2005 & 15 & 3.76 & 0.34 & 15 & 4.55 & 0.32 & & — & -2.33 & {$[-3.28 ;-1.37]$} & $4.3 \%$ \\
\hline Mao and Zhong 2010 & 30 & 50.00 & 22.00 & 30 & 95.00 & 23.00 & & 曰 & -1.97 & {$[-2.60 ;-1.35]$} & $5.1 \%$ \\
\hline Ren 2010 & 23 & 3.52 & 0.71 & 18 & 4.26 & 0.06 & & † & -1.36 & {$[-2.05 ;-0.67]$} & $4.9 \%$ \\
\hline Packham 2012 & 144 & -0.02 & 0.57 & 142 & 0.01 & 0.58 & & & -0.05 & {$[-0.28 ; 0.18]$} & $5.7 \%$ \\
\hline Kang 2013 & 33 & 4.14 & 0.25 & 60 & 4.46 & 1.17 & & 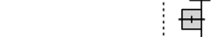 & -0.33 & {$[-0.76 ; 0.10]$} & $5.4 \%$ \\
\hline Dakhli macro 2016 & 26 & 4.12 & 0.41 & 16 & 4.43 & 0.94 & & Ð & -0.46 & {$[-1.09 ; 0.17]$} & $5.0 \%$ \\
\hline Dakhli micro 2016 & 45 & 3.79 & 0.92 & 26 & 4.04 & 0.66 & & 世 & -0.30 & {$[-0.78 ; 0.19]$} & $5.3 \%$ \\
\hline $\begin{array}{l}\text { Random effects model } \\
\text { Heterogeneity: } I^{2}=93 \%, \tau \\
\text { Test for effect in subgroup: }\end{array}$ & $\begin{array}{l}331 \\
=0.91 \varepsilon \\
z=-3.6\end{array}$ & $\begin{array}{l}85, x_{7}^{2}=97 \\
65(p<0.0\end{array}$ & $\begin{array}{l}7.33(p< \\
01)\end{array}$ & $\begin{array}{r}322 \\
0.01)\end{array}$ & & & & & -1.34 & {$[-2.07 ;-0.62]$} & $37.9 \%$ \\
\hline Random effects model & 1221 & & & 1112 & & & & $\dot{\theta}$ & -1.28 & {$[-1.67 ;-0.90]$} & $100.0 \%$ \\
\hline Heterogeneity: $I^{2}=93 \%, \tau^{2}$ & $=0.66 \mathrm{~s}$ & $93, \chi_{20}^{2}=2$ & $279.99(p$ & $<0.01)$ & & $\Gamma$ & 1 & 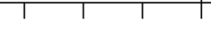 & & & \\
\hline $\begin{array}{l}\text { Residual heterogeneity: } I^{2} \\
\text { Test for overall effect: } z=-\end{array}$ & $\begin{array}{l}=93 \%, 2 \\
6.50(p\end{array}$ & $\begin{array}{l}\chi_{19}^{2}=279 . \\
<0.01)\end{array}$ & $69(p<0$ & & & -10 & -8 & 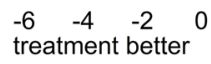 & ${ }_{\text {control } k}^{2}$ & & \\
\hline
\end{tabular}

Fig. 12 Forest plot of comparison: Sulodexide versus controls in renal complications of diabetes; change in urinary albumin excretion rate stratified by risk of bias, using the random effects model and the standardized mean difference; "micro" and "macro" denote the results in the

subgroup differences), nevertheless the estimated effects were quite well separated, with a smaller gain versus the controls when ACE inhibitors/ARB were used $(-0.91 ; 95 \%$ CI -1.44 to $-0.39 ; p<0.01)$ than in the other trials $(-1.53 ; 95 \%$ CI -1.66 to -0.86 ; $p<0.01)$. Furthermore, the subjects reported as using ACE inhibitors/ARB were clearly identified, while the studies on the class defined as "no/mixed/NA" included subgroups clearly identified as not using ACE inhibitors/ARB [89], but for the most part included subjects using and not using ACE inhibitors/ARB without reporting the outcomes separately, or failed to report whether ACE inhibitors/ARB were in use or not. This issue appears to deserve additional investigations. microalbuminuria and macroalbuminuria subgroups, respectively, where both subgroups were monitored and reported. Distribution of cases by albuminuria level is reported in Supplementary Table S3

Treatment Effect by Administration Schedule One of the issues periodically raised about the treatment with sulodexide concerned the most appropriate treatment schedule. The schedules tested in the examined trials included different administration routes (parenteral only; parenteral followed by oral administration; oral administration only), different doses (ranging from 600 LRU daily parenterally, up to 4000 LRU daily per os), and different treatment durations (from 3 weeks to 24 months).

To date, a clear answer to the issue is not available. The meta-analysis of outcomes stratified by administration route (Fig. 16) confirmed a significant effect by parenteral administration $(-1.77 ; 95 \% \quad$ CI -2.62 to $-0.92 ; p<0.01)$, parenteral followed by oral 


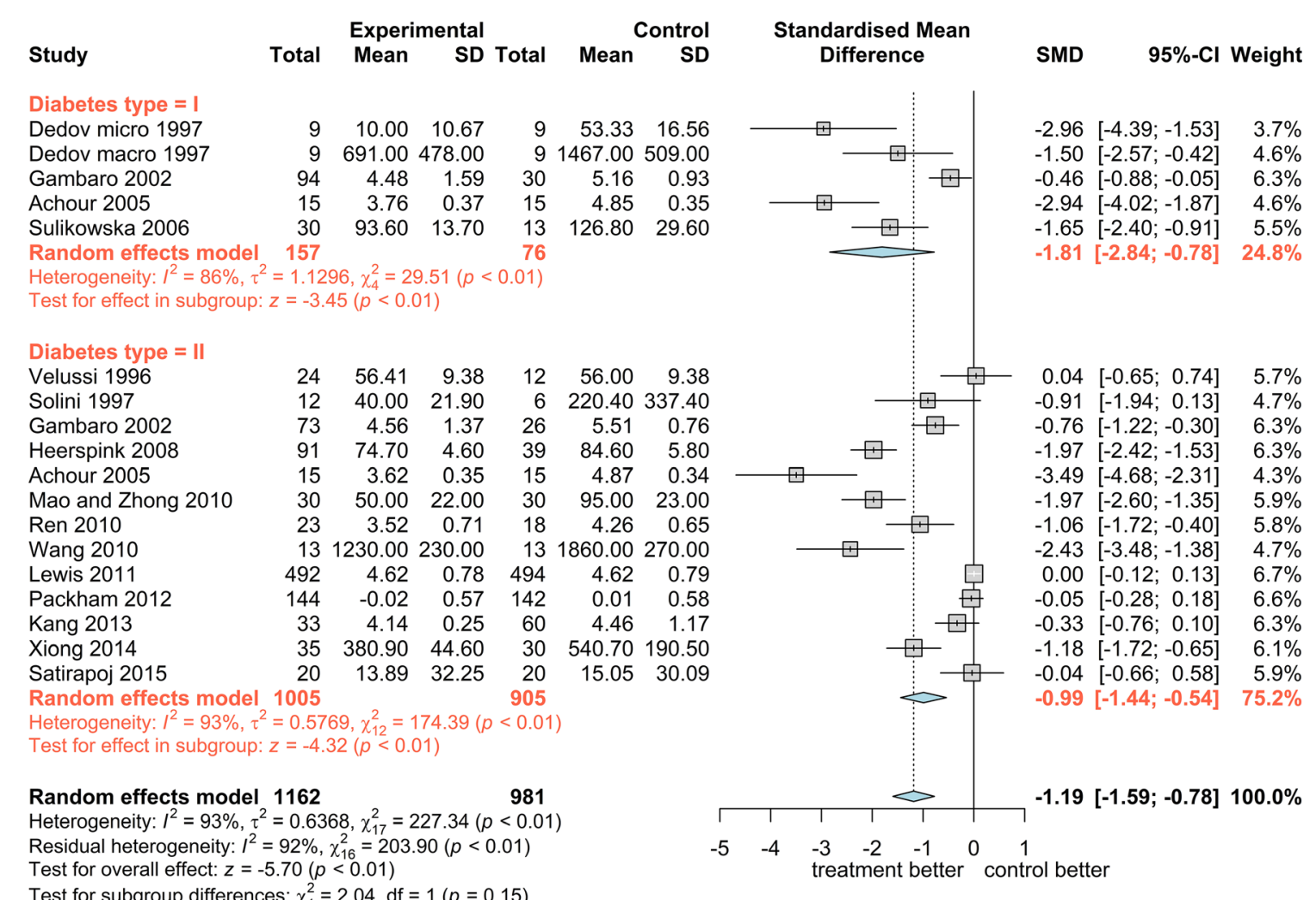

Fig. 13 Forest plot of comparison: Sulodexide versus controls in renal complications of diabetes; change in urinary albumin excretion rate, using the random effects model and the standardized mean difference, stratified by

administration $\quad(-0.89 ; \quad 95 \% \quad \mathrm{CI}-1.49$ to $-0.29 ; p<0.01)$, as well as by oral administration $(-1.25 ; 96 \% \mathrm{CI}-1.66$ to $-0.84 ; p<0.01)$, without evidence of differences between subgroups $(p=0.25)$. Three small studies specifically examined the effect of parenteral and oral treatment and failed to find an appreciable difference in outcome (Fig. 17).

Unfortunately, also the meta-analysis of the outcome stratified by dose failed to yield a clear response on the dose-effect relationship. The three ranges of doses used all resulted in a significant effect (Fig. 18): -1.40 (95\% CI -2.00 to $-0.79 ; p<0.01$ ) for the dose of $500 / 600$ LRU per day; -1.30 (95\% CI -2.03 to -0.57 ; $p<0.01$ ) for the dose of $1000 / 1200$ LRU per day, and -0.91 (95\% CI -1.58 to -0.24 ; $p<0.01$ ) for the dose of $2000 / 4000$ LRU per day. There was no evidence of a difference

diabetes type; "micro" and "macro" denote the results in the microalbuminuria and macroalbuminuria subgroups, respectively, where both subgroups were monitored and separately reported

between subgroups $(p=0.56)$. At first glance, it appeared that the higher doses resulted in less important outcomes; however, also in this case the confounding effect of using ACE inhibitors/ $\mathrm{ARB}$ appears to have played an important role. Indeed, among the five studies using this dose range, four used ACE inhibitors/ARB at maximal dose in all patients $[92,97,99,101]$ and the last [89] used ACE inhibitors/ARB in 52\% of patients. On the other hand, neither of the two studies that used different doses in parallel groups showed a definite dose-effect relationship: one [89] reported a trend for a greater effect of the higher dose but without exploring the relationship in detail; the other [92] was largely underpowered to detect such a relationship.

We further examined the possible change of effect intensity by duration of treatment, but 


\begin{tabular}{|c|c|c|c|c|c|c|c|c|c|c|c|}
\hline \multirow[b]{2}{*}{ Study } & \multirow[b]{2}{*}{ Total } & \multicolumn{2}{|c|}{ Experimental } & \multicolumn{3}{|r|}{ Control } & \multirow{2}{*}{\multicolumn{2}{|c|}{$\begin{array}{l}\text { Standardised Mean } \\
\text { Difference }\end{array}$}} & \multirow[b]{2}{*}{ SMD } & \multirow[b]{2}{*}{$95 \%-\mathrm{Cl}$} & \multirow[b]{2}{*}{ Weight } \\
\hline & & Mean & SD & Total & Mean & SD & & & & & \\
\hline \multicolumn{12}{|c|}{ Albuminuria level = micro } \\
\hline Velussi 1996 & 24 & 56.41 & 9.38 & 12 & 70.78 & 9.48 & & & -1.49 & {$[-2.28 ;-0.71]$} & $4.7 \%$ \\
\hline Dedov 1997 & 9 & 9.59 & 10.67 & 9 & 53.33 & 16.56 & & — & -2.99 & {$[-4.43 ;-1.55]$} & $3.2 \%$ \\
\hline Solini 1997 & 12 & 40.00 & 21.90 & 6 & 220.40 & 337.40 & & & -0.91 & {$[-1.94 ; 0.13]$} & $4.1 \%$ \\
\hline Gambaro 2002 & 106 & 3.59 & 1.70 & 30 & 4.33 & 0.99 & & 曰 & -0.47 & {$[-0.88 ;-0.06]$} & $5.5 \%$ \\
\hline Achour 2005 & 15 & 3.76 & 0.34 & 15 & 4.55 & 0.32 & & — & -2.33 & {$[-3.28 ;-1.37]$} & $4.3 \%$ \\
\hline Sulikowska 2006 & 30 & 93.60 & 13.70 & 13 & 126.80 & 29.60 & & $\rightleftarrows$ & -1.65 & {$[-2.40 ;-0.91]$} & $4.8 \%$ \\
\hline Heerspink 2008 & 91 & 74.70 & 4.60 & 39 & 84.60 & 5.80 & & 母 & -1.97 & {$[-2.42 ;-1.53]$} & $5.4 \%$ \\
\hline Mao and Zhong 2010 & 30 & 50.00 & 22.00 & 30 & 95.00 & 23.00 & & $\square$ & -1.97 & {$[-2.60 ;-1.35]$} & $5.1 \%$ \\
\hline Ren 2010 & 23 & 3.52 & 0.71 & 18 & 4.26 & 0.06 & & 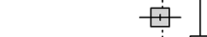 & -1.36 & {$[-2.05 ;-0.67]$} & $4.9 \%$ \\
\hline Lewis 2011 & 492 & 4.62 & 0.78 & 494 & 4.62 & 0.79 & & & 0.00 & {$[-0.12 ; 0.13]$} & $5.8 \%$ \\
\hline He and Ge 2012 & 33 & 78.44 & 43.22 & 33 & 129.50 & 40.81 & & $\exists$ & -1.20 & {$[-1.73 ;-0.67]$} & $5.3 \%$ \\
\hline Kang 2013 & 33 & 4.14 & 0.25 & 60 & 4.46 & 1.17 & & 4 & -0.33 & {$[-0.76 ; 0.10]$} & $5.4 \%$ \\
\hline Xiong 2014 & 35 & 380.90 & 44.60 & 30 & 540.70 & 190.50 & & 4 & -1.18 & {$[-1.72 ;-0.65]$} & $5.3 \%$ \\
\hline Satirapoj 2015 & 20 & 13.89 & 32.25 & 20 & 15.05 & 30.09 & & & -0.04 & {$[-0.66 ; 0.58]$} & $5.1 \%$ \\
\hline Dakhli 2016 & 45 & 3.79 & 0.92 & 26 & 4.04 & 0.66 & & ॄ & -0.30 & {$[-0.78 ; 0.19]$} & $5.3 \%$ \\
\hline \multicolumn{12}{|c|}{$\begin{array}{l}\text { Heterogeneity: } I^{2}=92 \%, \tau^{2}=0.6917, \chi_{14}^{2}=185.52(p<0.01) \\
\text { Test for effect in subgroup: } z=-4.89(p<0.01)\end{array}$} \\
\hline \multicolumn{12}{|c|}{ Albuminuria level = macro } \\
\hline Dedov 1997 & 9 & 691.00 & 478.00 & 9 & 1467.00 & 509.00 & & 世 & -1.50 & {$[-2.57 ;-0.42]$} & $4.0 \%$ \\
\hline Gambaro 2002 & 61 & 6.10 & 0.91 & 26 & 7.02 & 0.51 & & $\bigoplus$ & -1.12 & {$[-1.61 ;-0.63]$} & $5.3 \%$ \\
\hline Achour 2005 & 15 & 3.64 & 0.20 & 15 & 5.16 & 0.20 & 世 & - & -7.50 & {$[-9.65 ;-5.34]$} & $2.1 \%$ \\
\hline Wang 2010 & 13 & 1230.00 & 230.00 & 13 & 1860.00 & 27.00 & & 巴 & -3.73 & {$[-5.07 ;-2.38]$} & $3.4 \%$ \\
\hline Packham 2012 & 144 & -0.02 & 0.57 & 142 & 0.01 & 0.58 & & & -0.05 & {$[-0.28 ; 0.18]$} & $5.7 \%$ \\
\hline Dakhli 2016 & 26 & 4.12 & 0.41 & 16 & 4.43 & 0.94 & & $\square$ & -0.46 & {$[-1.09 ; 0.17]$} & $5.1 \%$ \\
\hline $\begin{array}{l}\text { Random effects model } \\
\text { Heterogeneity: } I^{2}=94 \%, \tau^{2} \\
\text { Test for effect in subgroup: }\end{array}$ & $\begin{array}{rl} & 268 \\
2 & 1.60 \\
z & =-3\end{array}$ & $\begin{array}{l}73, x_{5}^{2}=86 \\
49(p<0 . c\end{array}$ & $\begin{array}{l}6.1(p<c \\
01)\end{array}$ & 221 & & & & 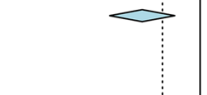 & -1.97 & {$[-3.07 ;-0.86]$} & $25.7 \%$ \\
\hline \multirow{3}{*}{\multicolumn{5}{|c|}{$\begin{array}{l}\text { Random effects model } 1266 \quad 1056 \\
\text { Heterogeneity: } I^{2}=93 \%, \tau^{2}=0.6759, \chi_{20}^{2}=271.72(p<0.01) \\
\text { Residual heterogeneity: } I^{2}=93 \%, \chi_{19}^{2}=271.62(p<0.01) \\
\text { Test for overall effect: } z=-6.43(p<0.01)\end{array}$}} & & & & $\dot{\phi}$ & \multirow{2}{*}{\multicolumn{2}{|c|}{$-1.28[-1.67 ;-0.89]$}} & $100.0 \%$ \\
\hline & & & & & & Г & 1 & 1 & & & \\
\hline & & & & & & -10 & -8 & $\begin{array}{l}-6 \\
\text { treatment better }\end{array}$ & control b & & \\
\hline
\end{tabular}

Fig. 14 Forest plot of comparison: Sulodexide versus controls in renal complications of diabetes; change in urinary albumin excretion rate, using the random effects model and the standardized mean difference, stratified by level of albuminuria

this approach also failed to detect a definite correlation between treatment duration and effect (Fig. 19). The point estimate of the effect by duration showed an overall trend for greater effect at longer duration, but this trend was not statistically significant $(p=0.31)$, essentially because of the impact of the only study at very long duration [99]. The two studies that measured the outcome at different times indicated, however, a significantly greater effect of the longer treatment: $-0.41 ; 95 \% \mathrm{CI}-0.51$ to $-0.31 ; p<0.01$ (Fig. 20).

Several studies monitored 434 patients for an average of 3 months ( 6 weeks to 6 months) of untreated follow-up after having concluded the treatment with sulodexide. Urinary albumin excretion returned to significantly higher levels after the end of treatment (Fig. 21), in some instances up to the pre-study level [73, 74, 84].
Overall, the analyses of the studies reporting data on the effect of sulodexide in the management of diabetic nephropathy monitored as urinary albumin excretion indicated that it significantly decreased albuminuria in comparison with controls, even though two large studies failed to observe an effect. It should be mentioned that sulodexide was also used in other forms of nephropathy (chronic glomerulonephritis [128] and prevention of transient nephropathy by contrast media [129]), with apparently a favorable effect.

\section{Number of Patients with Adverse Events}

Only few among the included studies reported in detail the information on subjects with AEs, and with a rather heterogeneous approach not only between RCTs and non-comparative 


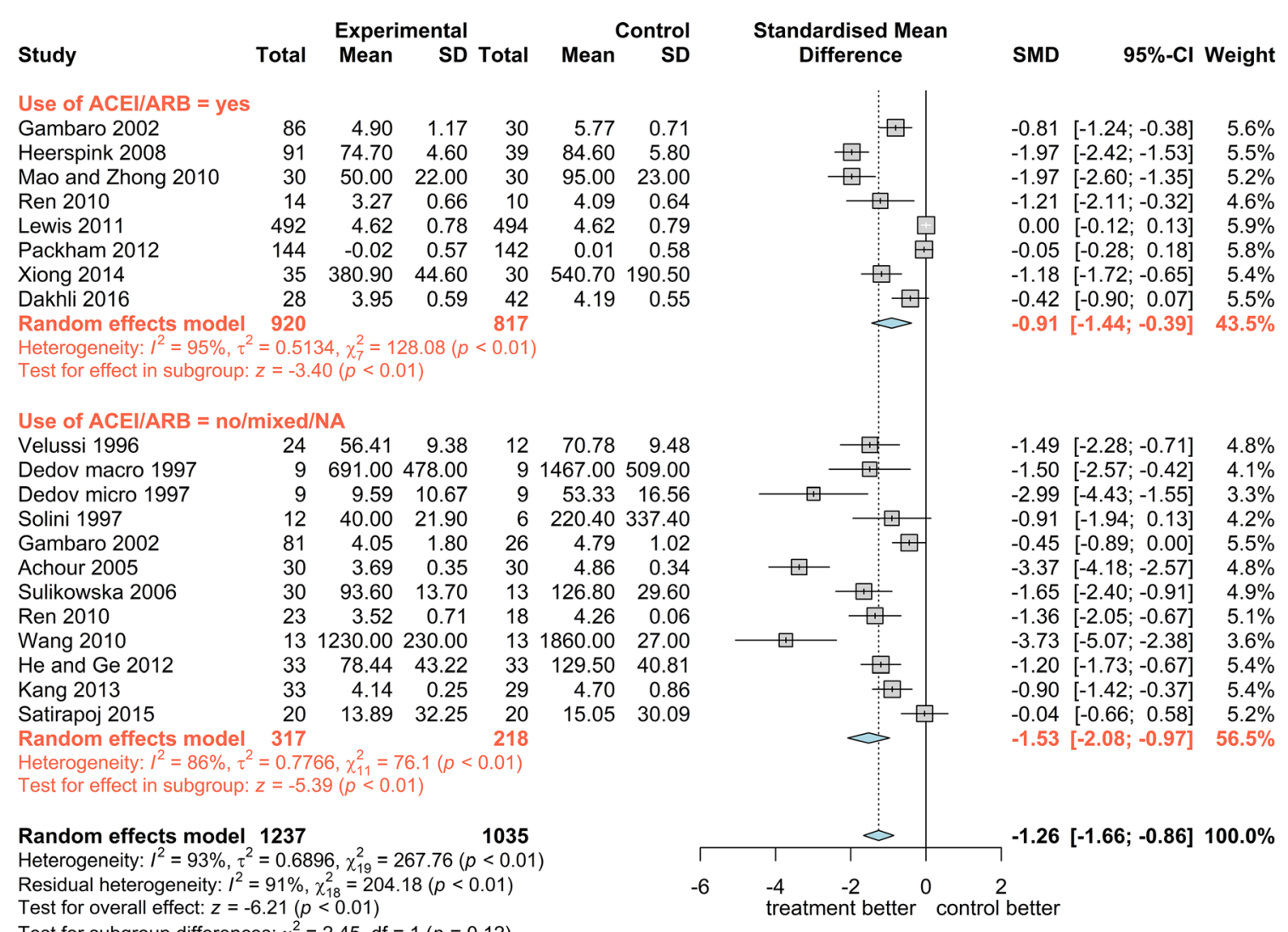

Fig. 15 Forest plot of comparison: Sulodexide versus controls in renal complications of diabetes; change in urinary albumin excretion rate, using the random effects model and the standardized mean difference, stratified by

studies but also within the RCTs (Supplementary Table S5).

Overall, the incidence of AEs could be estimated at about 5\% (95\% CI 2-8\%; Fig. 22), with a great heterogeneity. The heterogeneity was mostly due to differences between RCTs and non-RCT studies, with the former reporting an incidence of $9 \%$ (95\% CI $5-13 \%)$ versus $1 \%$ (95\% CI 0-3\%; Fig. 23). There was, however, no evidence of a different incidence of AEs between sulodexide and the controls in the comparative trials: the risk ratio was $0.907 \quad(95 \%$ CI 0.699-1.176; $p=0.46$; Fig. 24). use of ACE inhibitors/ARBs; "micro" and "macro" denote the results in the microalbuminuria and macroalbuminuria subgroups, respectively, where separately reported in the same study

\section{DISCUSSION}

\section{Summary of Main Results}

We examined and evaluated the existing evidence on the efficacy and safety of sulodexide used in the complications of diabetes: retinopathy, peripheral vascular disorders, and micro- and macroalbuminuric nephropathy.

This systematic review included 45 studies with 2817 participants; four studies with 213 subjects were relevant to retinopathy; eight studies with 188 subjects were performed on peripheral vascular disorders; 34 studies with 2378 subjects with diabetes studied the effect on nephropathy. Of these trials, 25 were RCTs.

The data retrieved on the management of retinopathy were insufficient to draw a definite 


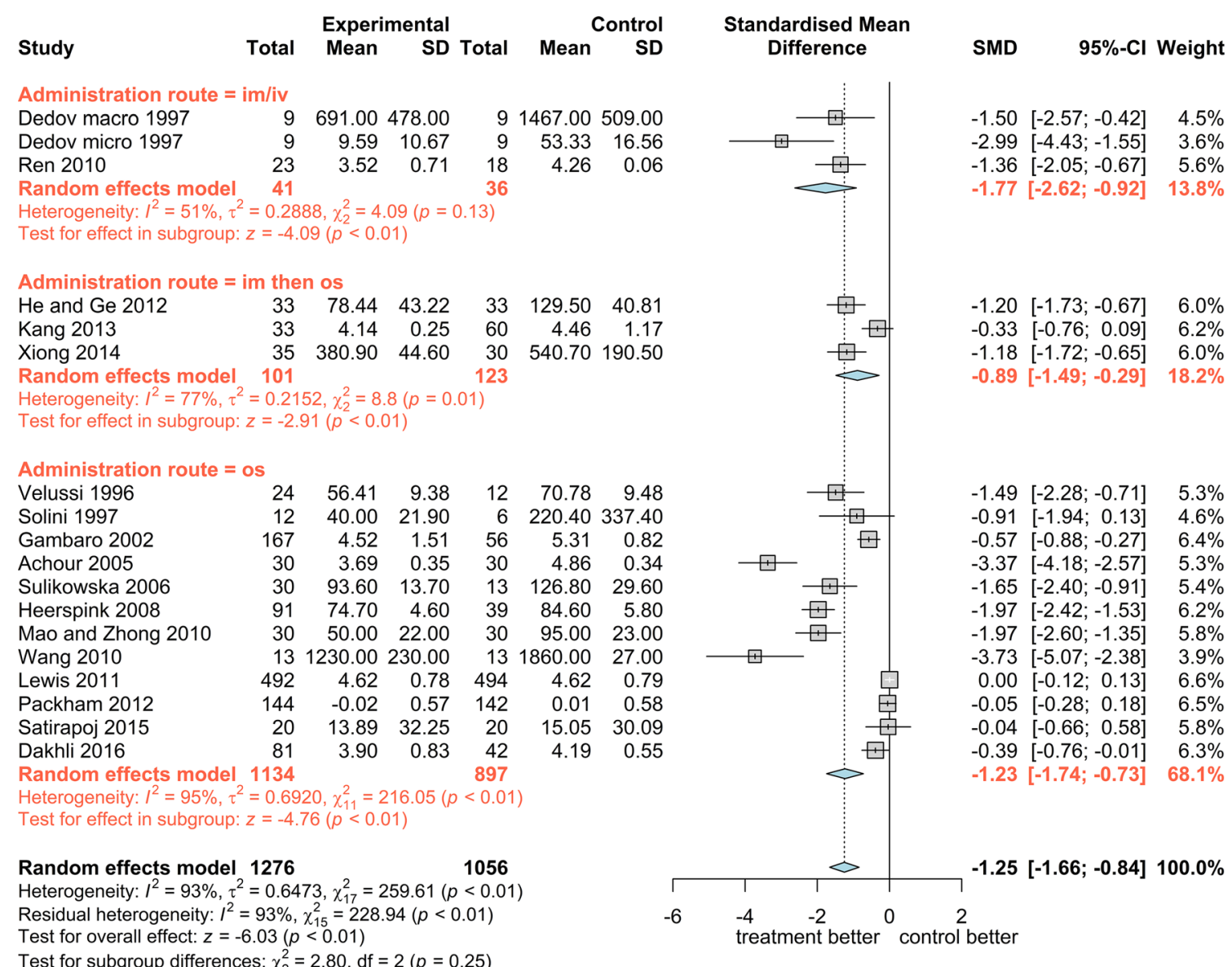

Fig. 16 Forest plot of comparison: Sulodexide versus controls in renal complications of diabetes; change in urinary albumin excretion rate, using the random effects model and the standardized mean difference, stratified by administration route; "micro" and "macro" denote the microalbuminuria and macroalbuminuria subgroups, respectively, where separately reported in the same study

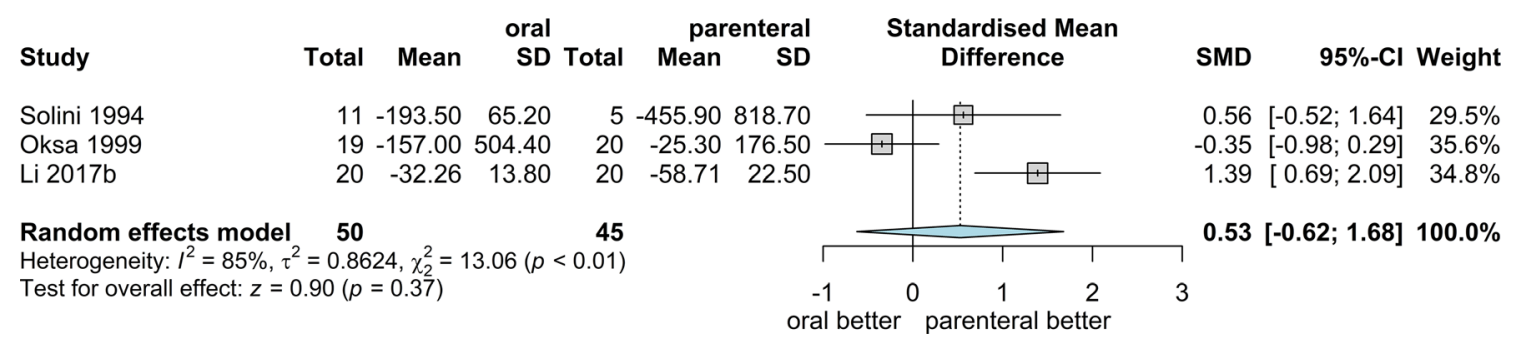

Fig. 17 Forest plot of comparison. Sulodexide in renal complications of diabetes; comparison of the mean change in urinary albumin excretion rate by administration route, using the random effects model and the standardized mean difference

conclusion, even though there is sufficient evidence to consider that the therapy with sulodexide over 4-12 months can reduce the retinal microvascular abnormalities, hard exudates, and hemorrhages in non-proliferative diabetic retinopathy; regression of associated macular edema was also observed. 


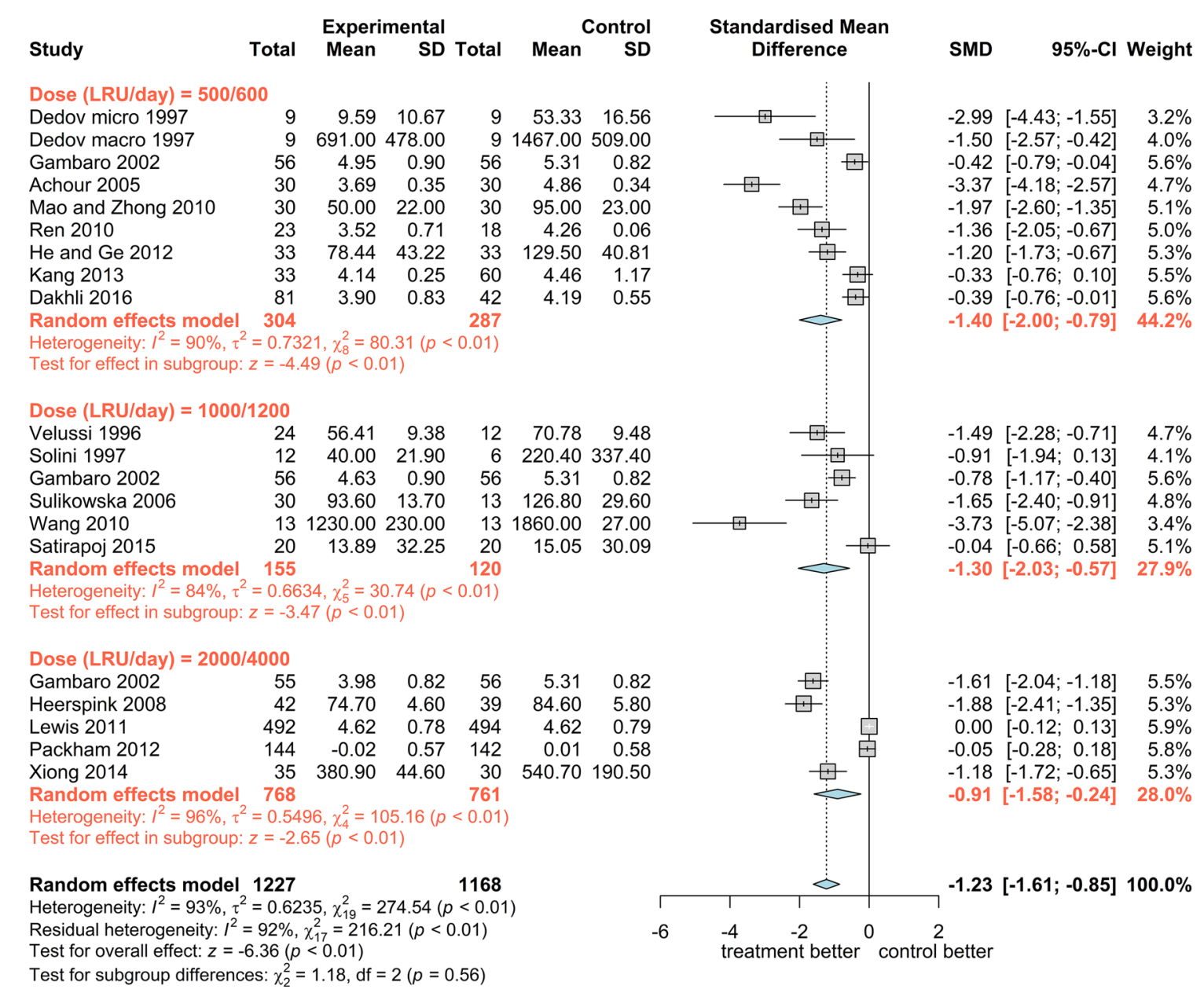

Fig. 18 Forest plot of comparison: Sulodexide versus controls in renal complications of diabetes; change in urinary albumin excretion rate, using the random effects model and the standardized mean difference, stratified by

We found instead sufficient evidence from good quality studies that sulodexide increased the pain-free walking distance by $52 \mathrm{~m}$ (95\% CI 49-55 $\mathrm{m}$ ) and the maximal walking distance by $130 \mathrm{~m}$ (95\% CI 127-135 m) in subjects with diabetes and peripheral angiopathy and claudication. In patients with diabetes and leg ulcers, sulodexide accelerated the healing by 27 days (95\% CI 23-31 days); treated patients experienced a risk ratio for healing within 2 months which was 1.8 times higher (95\% CI 1.4-2.4) compared with control subjects. The favorable effect of sulodexide on PAD is particularly interesting since no interventional study with the "traditional" and new antidiabetic drugs has

prevalent daily dose; "micro" and "macro" denote the microalbuminuria and macroalbuminuria subgroups, respectively

specifically addressed this condition so far. On the contrary, concerns have been raised about the safety of SGLT2 inhibitors in reference to peripheral angiopathy [9]. PAD is a severe longterm disabling complication of diabetes, primary cause of exertional pain, chronic pain, walking limitation, limb amputation, and gangrene. As a consequence, $\mathrm{PAD}$ is an important cause of reduced quality of life [130]. Although few deaths are directly attributed to PAD, it is also a potent predictor of mortality [131].

The trials on diabetic nephropathy were numerous but heterogeneous and of mixed quality. Overall, there was definite evidence that sulodexide decreased the urinary albumin 


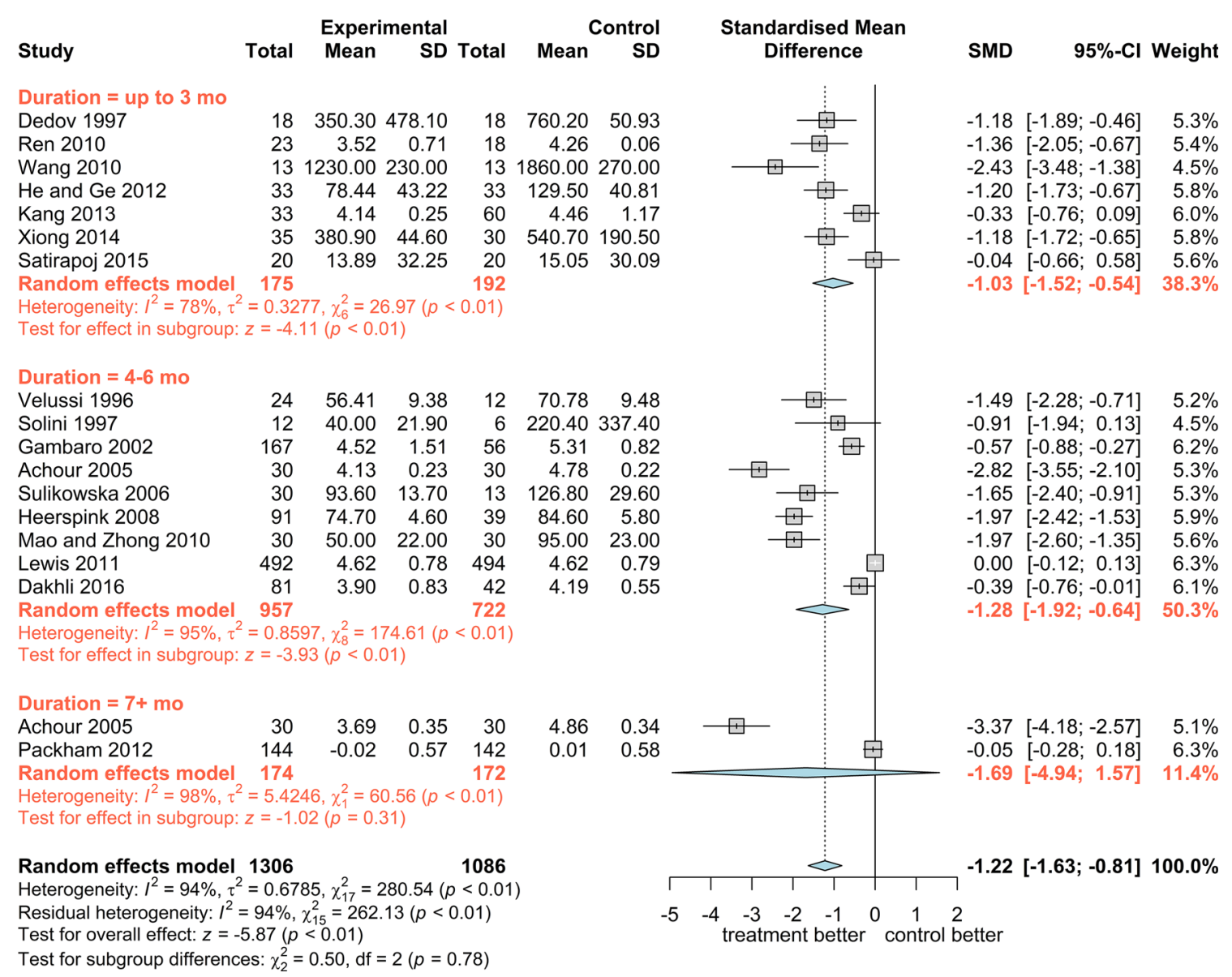

Fig. 19 Forest plot of comparison: Sulodexide versus controls in renal complications of diabetes; change in urinary albumin excretion rate, using the random effects model and the standardized mean difference, stratified by treatment duration

excretion rate with a standardized effect of - 1.07 (95\% CI - 1.30 to - 0.85). In comparison with controls, sulodexide decreased the urinary albumin excretion rate by a standardized size of -1.28 (95\% CI -1.67 to -0.90$)$.

The results were not significantly affected by the study quality and design; the effect of sulodexide was significantly greater than that of controls in type 1 and type 2 diabetes; in microand macro-albuminuria; with and without coadministration of ACE inhibitors/ARBs and regardless of dose, administration route, and length of treatment. There is sufficient indication that the parenteral treatment in this indication has no substantial advantages over the oral treatment $[73,86,105,131]$ and that the effect is likely to be greater for longer treatment duration $[90,93]$. There is no strong evidence of a dose-effect relationship over the used doses, even though the high-dose trials yielded results to be interpreted with care because of the impact of inconclusive trials performed with a different source of the raw material than all the other trials, and in patients under maximal ACE inhibitors/ARB dose $[97,99]$. There is, however, some indication that doses of less than 1000 LRU per day are likely to be less effective [89]. Although the available evidence is contrasting, the meta-analysis of the follow-up data indicates that the effect lasted only during the treatment period or, at most, for a short period after its end, whereas there is evidence that after 3 months on average after the end of treatment the level of albuminuria increased, in some cases to the pre-study level.

Two trials have negatively impacted on the consideration of sulodexide as an efficacious drug for the prevention and cure of diabetic 


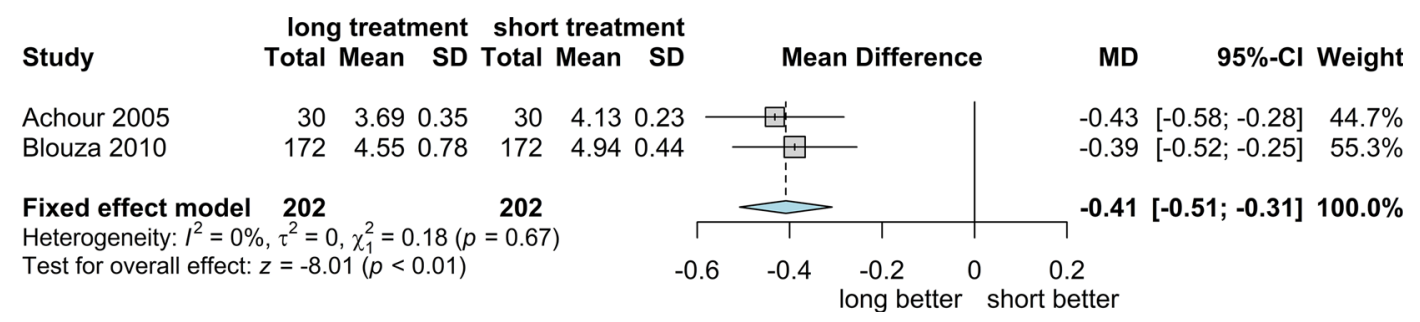

Fig. 20 Forest plot of comparison. Sulodexide in renal complications of diabetes; direct comparison of the mean change in urinary albumin excretion rate by duration of treatment, using the random effects model

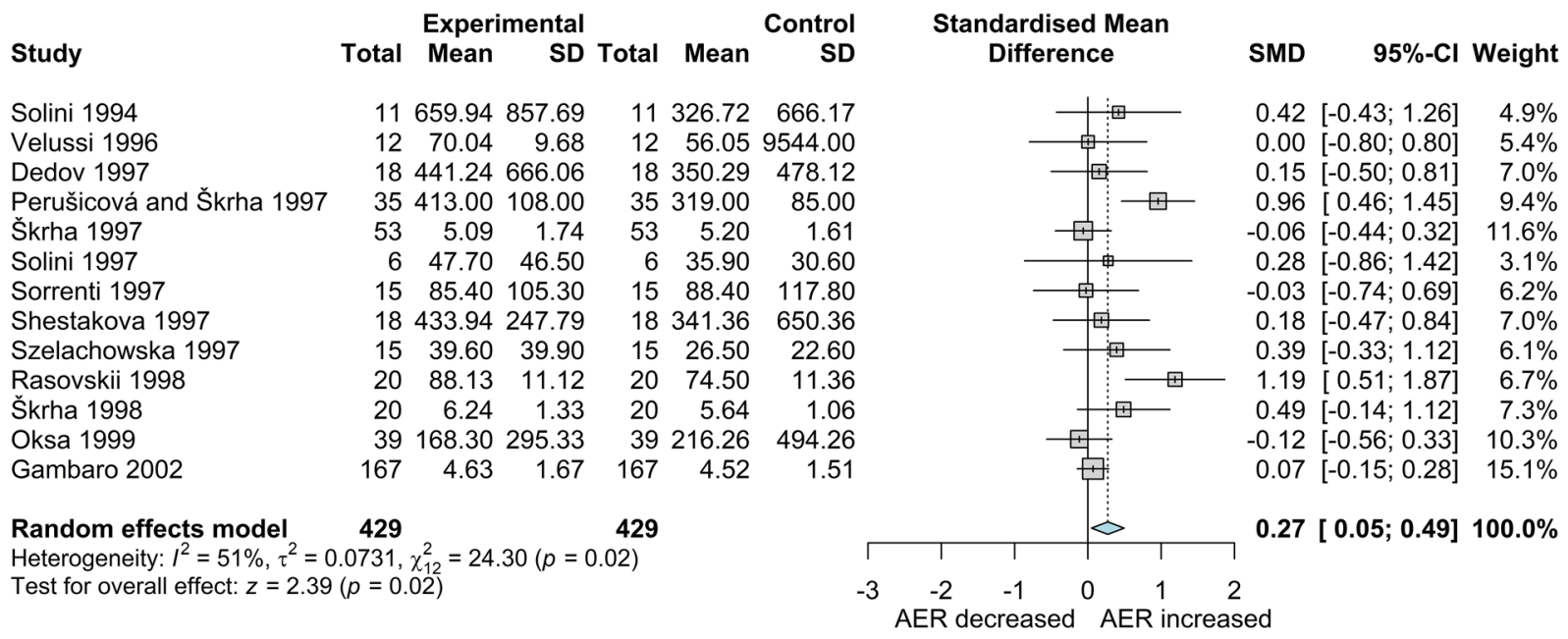

Fig. 21 Forest plot of comparison. Sulodexide in renal complications of diabetes; direct comparison of the mean change in urinary albumin excretion rate during the untreated follow-up period, using the random effects model and

nephropathy [97, 99]. Although their design and methodology were rigorous, a number of concerns were raised on the decision to suspend them after an ad interim analysis for lack of results $[126,127]$. However, two recent Bayesian meta-analyses have put the results of those two trials in a better light. In fact, the early treatment effects of sulodexide on albuminuria at 6 or 12 months and on glomerular filtration rate (GFR) slope over 3 years, a surrogate end point for kidney disease progression, were on the same regression lines of association of treatment effect with clinical endpoints [132, 133]. The treatment with sulodexide appears, therefore, likely to result in a substantially decreased risk of end-stage kidney disease (ESKD). standardized mean difference. 'Experimental' denotes the end of the untreated follow-up period; "Control" denotes the end of the treatment period

Safety was examined via the number of patients reporting AEs. As usual, there was a significant difference in proportion of patients reporting adverse events between RCTs and non-comparative studies. The proportion of patients with AEs was not different between sulodexide and controls and could be estimated at approximately 10\% (95\% CI 5-13\%).

\section{Overall Completeness and Applicability of Evidence}

Several limitations were identified in the included studies, some of which have already been mentioned. Most studies in nephropathy failed to properly classify the examined subjects or, if 


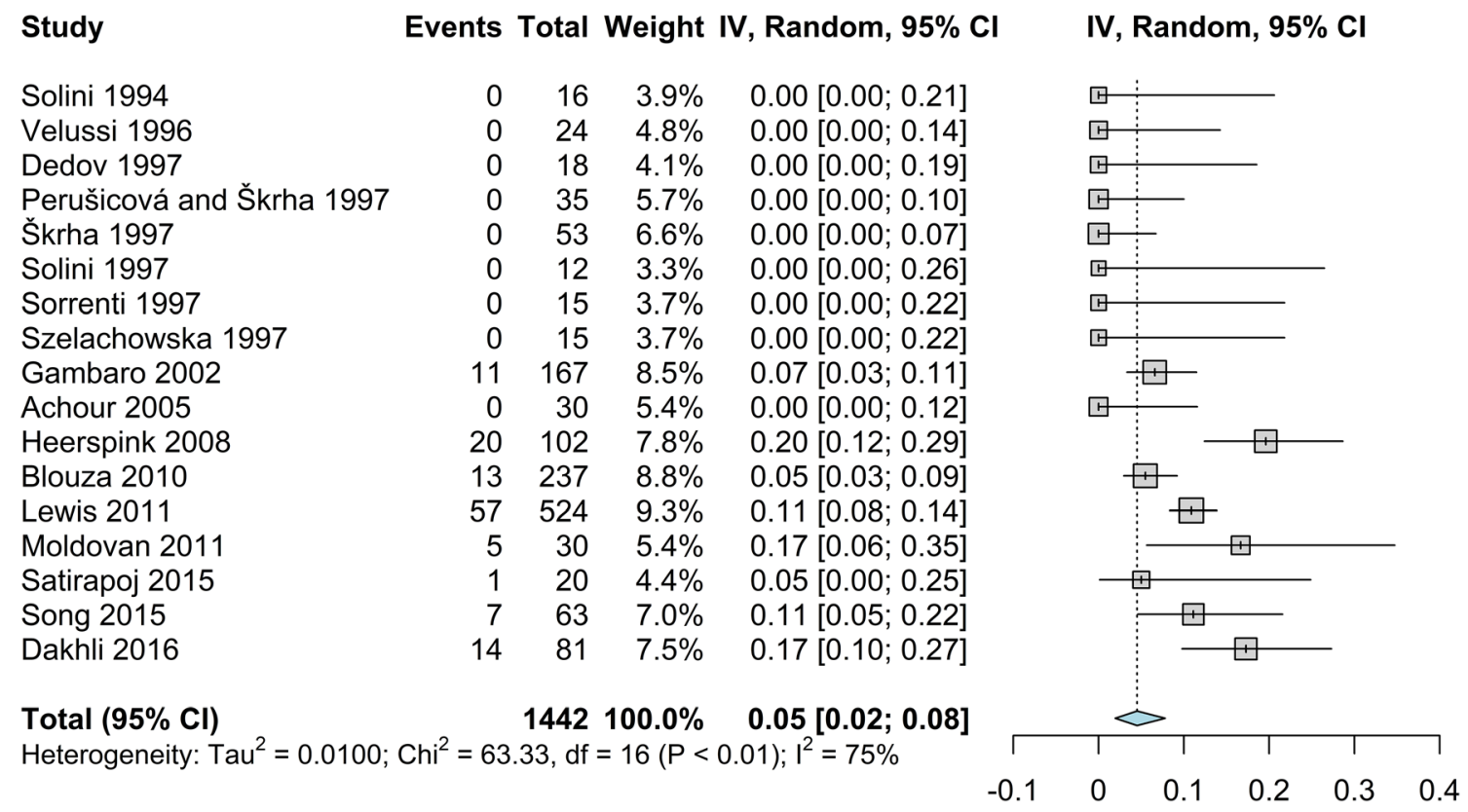

Fig. 22 Forest plot of comparison. Sulodexide in the complications of diabetes; incidence of adverse events, computed with the inverse variance method on the

classified, the results were not split by class. This was particularly relevant to the classifications by diabetes type, by degree of nephropathy as indicated by the level of albuminuria, by use and dosage of ACE inhibitors/ARB, which appeared to be one of the major confounders in the studies on diabetic nephropathy. Further, dose, administration route, and duration of treatment were not standardized across studies, introducing an additional level of confounding that could only be partially corrected by stratified analysis. On the other hand, the wide distribution of the studies across countries and healthcare systems favors the general applicability of the evidence.

\section{Potential Biases in the Review Process}

We tried to reduce to a minimum the potential biases but could not avoid some intrinsic problems. In the first instance, our database included all studies for which we could find enough reliable data to estimate the intended outcome, but this left out an additional 10\% of subjects who might have provided useful information.
Freeman-Tukey transformation and the random effects model. The confidence interval for individual studies was estimated using the Clopper-Pearson method

We also evaluated with care the risk of bias in the considered studies and performed an analysis of the impact of the level of risk on the estimate of the effect, without finding a significant impact. We could not, however, avoid a potential bias due to the need to perform transformations on the data, owing to the extreme heterogeneity of measures used in the different studies. These differences resulted in a relatively higher consistency within studies than between studies, producing the high heterogeneity observed. We did not apply corrections by level of glycemia and hypertension, both factors impacting on the complications of diabetes, since most studies reported that patients were included when stabilized for these two factors but the true extent of stabilization was not homogeneous across studies. Several studies reported data on hematology and blood chemistry that we decided not to analyze because the simple average failed to indicate whether AEs occurred. We also decided not to analyze the course of blood pressure, since it was already examined elsewhere [134].

An additional source of heterogeneity was the temporal window of the studies-more than 
two decades with the attending changes in therapeutic approach to these patients-and the variability of healthcare system. However, we decided not to apply adjustments by date and/ or healthcare system since these could have introduced an even larger bias.

\section{Agreements and Disagreements with Other Studies or Reviews}

The conclusions of this review do not substantially differ from those already published on sulodexide concerning the effect on chronic venous disease $[17,125,135]$ and renal complications of diabetes [112, 136, 137]. In comparison with these last reviews, our review investigated the results in more depth, included more studies, and examined the effect of different dosages, different administration schedules, and routes, as well as the duration of the hypoalbuminuric effect and whether the effect was different in patients with type 1 or type 2 diabetes.

To our knowledge, no systematic review on the effects of sulodexide on diabetic peripheral angiopathy and on diabetic retinopathy has been published to date.

\section{CONCLUSIONS}

\section{Implications for Practice}

Sulodexide was shown to be an effective treatment for the management of peripheral vascular complications in subjects with diabetes, because it increased the walking capacity and accelerated the healing of lower limb ulcers. Although there is some evidence supporting its utility in the diabetic foot, the available information is insufficient to draw a conclusion. Sulodexide was a useful treatment for patients with type 1 and type 2 diabetes and various degrees of nephropathy, because it reduced the urinary albumin excretion. It remains to be seen whether this effect changes with the degree of nephropathy and with the use of ACE inhibitors/ARBs and, if so, whether the effect is modulated by the dose of ACE inhibitors/ARB.
It also remains to be seen if and for how long the effect persists after the end of treatment. Although there is some evidence supporting the utility of sulodexide in diabetic retinopathy, further investigations are needed to attain conclusive evidence.

\section{Implications for Research}

To date, approaches to prevent the complications of diabetes are strict glycemic control and strict control of arterial hypertension. In case of renal involvement, inhibitors of the ACE or angiotensin II receptor blockers at maximal dose both in type 1 and type 2 diabetes, and SGLT2 inhibitors in type 2 diabetes, have been found useful to decrease the risk of ESKD. In secondary prevention of cardiovascular morbidities in patients with type 2 diabetes, GLP1RAs are certainly effective. However, there are still too many deaths and cardiovascular and ESKD events in patients with diabetes. Thus, there is room enough to add further effective treatments.

An interesting line of research would be the investigation of whether sulodexide really exerts a greater renal effect on type 1 diabetes than in type 2 diabetes. This hypothesis, elicited by the meta-analysis reported above, could be justified considering that in type 1 diabetes the nephropathy is essentially due to the diabetes only, whereas in type 2 diabetes it may often be heterogeneous in etiology, and therefore less susceptible to the effect of sulodexide. This would also be important considering that the therapeutic armamentarium for type 1 diabetes has not received any new-entry agent, with the recent breakthroughs, GLP-1RAs and SGLT2 inhibitors, being employed only in patients with type 2 diabetes.

Another point that might be investigated more deeply, subject to the cooperation of the investigators who performed the studies on sulodexide, would be an individual-patient meta-analysis, to examine in more homogeneous subgroups the most effective treatment regimen to be recommended.

In conclusion, further research should investigate which treatment, and to what 
extent, can help in preventing or managing the many complications of diabetes under real-life conditions, using all the available means to limit the burden of a disease that is becoming one of the main long-term risk factors for the general population.

\section{ACKNOWLEDGEMENTS}

Funding. The study was conducted with the support of Alfasigma, Italy, which did not affect the processing and the final results of this work. Alfasigma, Italy, is also supporting the journal's Rapid Service.

Medical Writing and/or Editorial Assistance. The authors thank Simone Tait and Sarah Greig, PhD, of Springer Healthcare Communications for preparing the manuscript for submission. This assistance was funded by Alfasigma Italy.

Authorship. All named authors meet the International Committee of Medical Journal Editors (ICMJE) criteria for authorship for this article, take responsibility for the integrity of the work as a whole, and have given their approval for this version to be published.

Disclosures. Angelo A. Bignamini received consultancy fees from Bayer Healthcare and from Alfasigma. Ahmed Chebil, Giovanni Gambaro and Jiř́ Matuška have nothing to disclose.

Compliance with Ethics Guidelines. This article is based on previously conducted studies and does not contain any studies with human participants or animals performed by any of the authors.

Data Availability. All data analyzed in this article are present in the original papers mentioned and are shown in the figures as original or derived data.

Open Access. This article is licensed under a Creative Commons Attribution-
NonCommercial 4.0 International License, which permits any non-commercial use, sharing, adaptation, distribution and reproduction in any medium or format, as long as you give appropriate credit to the original author(s) and the source, provide a link to the Creative Commons licence, and indicate if changes were made. The images or other third party material in this article are included in the article's Creative Commons licence, unless indicated otherwise in a credit line to the material. If material is not included in the article's Creative Commons licence and your intended use is not permitted by statutory regulation or exceeds the permitted use, you will need to obtain permission directly from the copyright holder. To view a copy of this licence, visit http:// creativecommons.org/licenses/by-nc/4.0/.

\section{REFERENCES}

1. DeFronzo RA, Ferrannini E, Zimmet P, Alberti KGMM. International textbook of diabetes mellitus. 4th ed. Hoboken: Wiley-Blackwell; 2015.

2. NCD Risk Factor Collaboration (NCD-RisC). Worldwide trends in diabetes since 1980: a pooled analysis of 751 population-based studies with 4.4 million participants. Lancet. 2016;387(10027): 1513-30. https://doi.org/10.1016/S01406736(16)00618-8.

3. International Diabetes Federation. IDF Diabetes Atlas, 8th edition 2017. http://www.diabetesatlas. org. Accessed 9 Apr 2020.

4. GBD 2017 Disease and Injury Incidence and Prevalence Collaborators. Global, regional, and national incidence, prevalence, and years lived with disability for 354 diseases and injuries for 195 countries and territories, 1990-2017: a systematic analysis for the Global Burden of Disease Study 2017. Lancet. 2018;392(10159):1789-858. https://doi.org/10. 1016/S0140-6736(18)32279-7.

5. Hewitt J, Castilla Guerra L, Fernández-Moreno MC, Sierra C. Diabetes and stroke prevention: a review. Stroke Res Treat. 2012;2012:673187. https:/doi. org/10.1155/2012/673187.

6. Thiruvoipati T, Kielhorn CE, Armstrong EJ. Peripheral artery disease in patients with diabetes: epidemiology, mechanisms, and outcomes. World J 
Diabetes. 2015;6(7):961-9. https://doi.org/10.4239/ wjd.v6.i7.961.

7. Zoungas S, Arima H, Gerstein HC, et al. Effects of intensive glucose control on microvascular outcomes in patients with type 2 diabetes: a metaanalysis of individual participant data from randomised controlled trials. Lancet Diabetes Endocrinol. 2017;5(6):431-7. https://doi.org/10.1016/ S2213-8587(17)30104-3.

8. Gaede P, Lund-Andersen H, Parving HH, Pedersen O. Effect of a multifactorial intervention on mortality in type 2 diabetes. N Engl J Med. 2008;358(6): 580-91. https://doi.org/10.1056/NEJMoa0706245.

9. Neal B, Perkovic V, Mahaffey KW, et al. Canagliflozin and cardiovascular and renal events in type 2 diabetes. N Engl J Med. 2017;377(7):644-57. https:// doi.org/10.1056/NEJMoa1611925.

10. Deckert T, Feldt-Rasmussen B, Borch-Johnsen K, Jensen T, Kofoed-Enevoldsen A. Albuminuria reflects widespread vascular damage. The Steno hypothesis. Diabetologia. 1989;32(4):219-26. https://doi.org/10.1007/BF00285287.

11. Dogné S, Flamion B, Caron N. Endothelial glycocalyx as a shield against diabetic vascular complications: involvement of hyaluronan and hyaluronidases. Arterioscler Thromb Vasc Biol. 2018;38(7):1427-39. https://doi.org/10.1161/ ATVBAHA.118.310839.

12. Abaterusso C, Gambaro G. The role of glycosaminoglycans and sulodexide in the treatment of diabetic nephropathy. Treat Endocrinol. 2006;5(4):211-22. https://doi.org/10.2165/ 00024677-200605040-00002.

13. Weiss R, Niecestro R, Raz I. The role of sulodexide in the treatment of diabetic nephropathy. Drugs. 2007;67(18):2681-96. https://doi.org/10.2165/ 00003495-200767180-00004.

14. Lewis EJ, Xu X. Abnormal glomerular permeability characteristics in diabetic nephropathy: implications for the therapeutic use of low-molecular weight heparin. Diabetes Care. 2008;31(Suppl 2): S202-7. https://doi.org/10.2337/dc08-s251.

15. Masola V, Zaza G, Gambaro G. Sulodexide and glycosaminoglycans in the progression of renal disease. Nephrol Dial Transplant. 2014;29(Suppl 1): i74-9. https://doi.org/10.1093/ndt/gft389.

16. Masola V, Zaza G, Onisto M, Lupo A, Gambaro G. Glycosaminoglycans, proteoglycans and sulodexide and the endothelium: biological roles and pharmacological effects. Int Angiol. 2014;33(3): 243-54.
17. Carroll BJ, Piazza G, Goldhaber SZ. Sulodexide in venous disease. J Thromb Haemost. 2019;17(1): 31-8. https://doi.org/10.1111/jth.14324.

18. Coccheri S, Mannello F. Development and use of sulodexide in vascular diseases: implications for treatment. Drug Des Dev Ther. 2013;8:49-65. https://doi.org/10.2147/DDDT.S6762.

19. Yung S, Chau MK, Zhang Q, Zhang CZ, Chan TM. Sulodexide decreases albuminuria and regulates matrix protein accumulation in C57BL/6 mice with streptozotocin-induced type I diabetic nephropathy. PLoS One. 2013;8(1):e54501. https://doi.org/ 10.1371/journal.pone.0054501.

20. Roshan-Milani S, Khalilpour J, Abdollahzade FA. The heparanase inhibitor (sulodexide) decreases urine glycosaminoglycan excretion and mitigates functional and histological renal damages in diabetic rats. Acta Med Bulg. 2019;46(2):41-6. https:// doi.org/10.2478/amb-2019-0017.

21. Gambaro G, Cavazzana AO, Luzi P, et al. Glycosaminoglycans prevent morphological renal alterations and albuminuria in diabetic rats. Kidney Int. 1992;42(2):285-91. https://doi.org/10.1038/ki. 1992.288 .

22. Gambaro G, Venturini AP, Noonan DM, et al. Treatment with a glycosaminoglycan formulation ameliorates experimental diabetic nephropathy. Kidney Int. 1994;46(3):797-806. https://doi.org/10. 1038/ki.1994.335.

23. Kristová V, Lísková S, Sotníková R, Vojtko R, Kurtanský A. Sulodexide improves endothelial dysfunction in streptozotocin-induced diabetes in rats. Physiol Res. 2008;57(3):491-4.

24. Li T, Liu X, Zhao Z, Ni L, Liu C. Sulodexide recovers endothelial function through reconstructing glycocalyx in the balloon-injury rat carotid artery model. Oncotarget. 2017;8(53):91350-61. https:// doi.org/10.18632/oncotarget.20518.

25. Liu YN, Zhou J, Li T, et al. Sulodexide protects renal tubular epithelial cells from oxidative stress-induced injury via upregulating klotho expression at an early stage of diabetic kidney disease. J Diabetes Res. 2017;2017:4989847. https://doi.org/10.1155/ $2017 / 4989847$.

26. Song JW, Zullo JA, Liveris D, Dragovich M, Zhang XF, Goligorsky MS. Therapeutic restoration of endothelial glycocalyx in sepsis. J Pharmacol Exp Ther. 2017;361(1):115-21. https://doi.org/10.1124/ jpet.116.239509.

27. Li T, Liu C. Sulodexide recovers endothelial function through reconstructing glycocalyx in the 
balloon-injury rat carotid artery model. Int Angiol. 2018;37:72.

28. Broekhuizen LN, Lemkes BA, Mooij HL, et al. Effect of sulodexide on endothelial glycocalyx and vascular permeability in patients with type 2 diabetes mellitus. Diabetologia. 2010;53(12):2646-55. https://doi.org/10.1007/s00125-010-1910-X.

29. Mannello F, Ligi D, Raffetto JD. Glycosaminoglycan sulodexide modulates inflammatory pathways in chronic venous disease. Int Angiol. 2014;33(3): 236-42.

30. Mannello F, Ligi D, Canale M, Raffetto JD. Sulodexide down-regulates the release of cytokines, chemokines, and leukocyte colony stimulating factors from human macrophages: role of glycosaminoglycans in inflammatory pathways of chronic venous disease. Curr Vasc Pharmacol. 2014;12(1):173-85. https://doi.org/10.2174/ 1570161111666131126144025 .

31. Ligi D, Mosti G, Croce L, Raffetto JD, Mannello F. Chronic venous disease-part I: inflammatory biomarkers in wound healing. Biochim Biophys Acta. 2016;1862(10):1964-74. https://doi.org/10. 1016/j.bbadis.2016.07.018.

32. Ligi D, Mosti G, Croce L, Raffetto JD, Mannello F. Chronic venous disease-part II: proteolytic biomarkers in wound healing. Biochim Biophys Acta. 2016;1862(10):1900-8. https://doi.org/10. 1016/j.bbadis.2016.07.011.

33. Ligi D, Benitez S, Croce L, et al. Electronegative LDL induces MMP-9 and TIMP-1 release in monocytes through CD14 activation: inhibitory effect of glycosaminoglycan sulodexide. Biochim Biophys Acta Mol Basis Dis. 2018;1864(12):3559-67. https://doi. org/10.1016/j.bbadis.2018.09.022.

34. Shu J, Zeng LY, Lin KY, et al. Renal protective effects of sulodexide in diabetic rats and its anti-oxidative mechanism. Nan Fang Yi Ke Da Xue Xue Bao. 2009;29(4):778-80.

35. Gabryel B, Jarzabek K, Machnik G, et al. Superoxide dismutase 1 and glutathione peroxidase 1 are involved in the protective effect of sulodexide on vascular endothelial cells exposed to oxygen-glucose deprivation. Microvasc Res. 2016;103:26-35. https://doi.org/10.1016/j.mvr.2015.10.001.

36. De Felice F, Megiorni F, Pietrantoni I, et al. Sulodexide counteracts endothelial dysfunction induced by metabolic or non-metabolic stresses through activation of the autophagic program. Eur Rev Med Pharmacol Sci. 2019;23(6):2669-80. https://doi.org/10.26355/eurrev_201903_17415.
37. Masola V, Onisto M, Zaza G, Lupo A, Gambaro G. A new mechanism of action of sulodexide in diabetic nephropathy: inhibits heparanase- 1 and prevents FGF-2-induced renal epithelial-mesenchymal transition. J Transl Med. 2012;10:213. https://doi.org/ 10.1186/1479-5876-10-213.

38. Xu G, Qin Q, Yang M, Qiao Z, Gu Y, Niu J. Heparanase-driven inflammation from the AGEs-stimulated macrophages changes the functions of glomerular endothelial cells. Diabetes Res Clin Pract. 2017;124:30-40. https://doi.org/10.1016/j. diabres.2016.12.016.

39. Giurdanella G, Lazzara F, Caporarello N, et al. Sulodexide prevents activation of the PLA2/COX-2/ VEGF inflammatory pathway in human retinal endothelial cells by blocking the effect of AGE/ RAGE. Biochem Pharmacol. 2017;142:145-54. https://doi.org/10.1016/j.bcp.2017.06.130.

40. Matuska J, Benova K. Development of wall stiffness parameters in diabetes mellitus type II-evaluation of therapeutic effect of sulodexide vs naftidrofuryl: an open controlled 2-year study. Vasa-Eur J Vasc Med. 2017;46:30. https://doi.org/10.1024/0301$1526 / \mathrm{a} 000651$.

41. Cha JJ, Kang YS, Hyun YY, et al. Sulodexide improves renal function through reduction of vascular endothelial growth factor in type 2 diabetic rats. Life Sci. 2013;92(23):1118-24. https://doi.org/ 10.1016/j.lfs.2013.04.008.

42. Tiurenkov IN, Voronkov AV, Slietsans AA, Snigur GL. Effects of mexidol and sulodexide on the level of specific markers of endothelial dysfunction in animals with experimental diabetes mellitus. Eksp Klin Farmakol. 2012;75(5):14-6.

43. Raffetto JD, Calanni F, Mattana P, Khalil RA. Sulodexide promotes arterial relaxation via endothelium-dependent nitric oxide-mediated pathway. Biochem Pharmacol. 2019;166:347-56. https://doi.org/10.1016/j.bcp.2019.04.021.

44. Condorelli M, Chiariello M, Dagianti A, et al. IPOV2: a prospective, multicenter, randomized, comparative clinical investigation of the effects of sulodexide in preventing cardiovascular accidents in the first year after acute myocardial infarction. J Am Coll Cardiol. 1994;23(1):27-34. https://doi. org/10.1016/0735-1097(94)90498-7.

45. Peterkova V, Mishina I, Sherbacheva L. Sulodexide in the treatment of diabetic nephropathy in children. Diabetes (Mosk). 1999;3:31-3.

46. Higgins JP, Thomas J, Chandler J, et al. Cochrane handbook for systematic reviews of interventions, version 6.0. New York: Wiley; 2019. 
47. Sterne JAC, Savović J, Page MJ, et al. RoB 2: a revised tool for assessing risk of bias in randomised trials. BMJ. 2019;366:14898. https://doi.org/10.1136/bmj. 14898.

48. Balduzzi S, Rucker G, Schwarzer G. How to perform a meta-analysis with R: a practical tutorial. Evid Based Ment Health. 2019;22(4):153-60. https://doi. org/10.1136/ebmental-2019-300117.

49. $\mathrm{R}$ Core Team. A language and environment for statistical computing. 2015. R foundation for statistical computation, Vienna, Austria. https://www. R-project.org/. Accessed 17 Mar 2020.

50. Higgins JP, Li T, Deeks JJ, et al. Choosing effect measures and computing estimates of effect, version 6.0. In: Higgins J, Thomas J, Chandler J, Cumpston M, Li T, Page M, et al., editors. Cochrane handbook for systematic reviews of interventions. New York: Wiley; 2019. p. 143-76.

51. Lipsey MW, Wilson DB. Practical meta-analysis. Thousand Oaks: SAGE; 2001.

52. Wan X, Wang W, Liu J, Tong T. Estimating the sample mean and standard deviation from the sample size, median, range and/or interquartile range. BMC Med Res Methodol. 2014;14:135. https://doi.org/10.1186/1471-2288-14-135.

53. Chen S, Wei M, Gao Y, et al. A randomized controlled trial of sulodexide for early diabetic nephropathy. Chin J Evid Based Med. 2008;8(3): 162-6. https://doi.org/10.7507/1672-2531. 20080037

54. Hu M, Lv B, Meng Y, Zhou J, Xu X, Xiao X. Therapeutic effects of sulodexide combined with irbesartan on elderly patients with diabetic nephropathy. Pract Geriatr. 2009;23(4):276-8.

55. Wang T-J, Wang Z-S, Yang F. Clinical observation of sulodexide in treatment of type 2 diabetes with early nephropathy. Med Pharm World. 2009;11: 769-71.

56. Hu M, Lv B, Meng Y, Zhou J, Xu X, Xiao X. Therapeutic effects of perindopril combined with sulodexide on elderly early patients with diabetic nephropathy. Southwest Nat Defence Med. 2010;20:501-3.

57. Liu S. Therapeutic effects of sulodexide combined with benazapril on patients with diabetic kidney disease. Chin J Diffic Compl Cas. 2011;10:21-2.

58. Ma J, Jiang H, Cui Q, Song B. Clinical observation of sulodexide in reducing microalbumi-nuria in diabetic nephropathy patients. Mod Prev Med. 2011;38:2918-9.
59. Zhang H, Kang P, Li J, et al. Study of the effect of Chulo on albuminuria in diabetic nephropathy. Med J Integr Tradit Chin West Med. 2011;20:405-6.

60. Huo S, Huang M, Liu Y. Clinical observation of sulodexide in treatment of in reducing proteinuria in type 2 diabetic nephropathy patients. Hebei Med J. 2014;36:191-2.

61. Chen L, Yang R. Effect of sulodexide on urine protein excretion in type 2 diabetes with proteinuria. Med J Wuhan Univ. 2015;34:450-2.

62. Rubbi F, Caramazza R, Boccia S, et al. The effects of sulodexide on diabetic retinopathy. Minerva Cardioangiol. 2000;48(Suppl 1):81-2.

63. Shadrichev F. The effect of diabetic nephropathy therapy with "Vessel Due F" (sulodexide) on the risk of intraocular hemorrhages in patients with proliferative diabetic retinopathy. Ophthalmol Gazette. 2009;2(2):49-53.

64. Song JH, Chin HS, Kwon OW, Lim SJ, Kim HK, DRESS Research Group. Effect of sulodexide in patients with non-proliferative diabetic retinopathy: diabetic retinopathy sulodexide study (DRESS). Graefes Arch Clin Exp Ophthalmol. 2015;253(6):829-37. https:// doi.org/10.1007/s00417-014-2746-8.

65. Belcaro G, Dugall M, Bradford HD, et al. Recurrent retinal vein thrombosis: prevention with aspirin, Pycnogenol ${ }^{\circledR}$, ticlopidine, or sulodexide. Minerva Cardioangiol. 2019;67(2):109-14. https://doi.org/ 10.23736/S0026-4725.19.04891-6.

66. Utratová J, Mayer J, Elbl L, Vorlícek J, Prásek J. Experience with sulodexide (Vessel Due F) in diabetics with ischemic disease of the lower extremities. Vnitr Lek. 1993;39(6):575-80.

67. Bregovsky V, Zalesskaya A. The use of sulodexide in obliterating atherosclerosis of the lower extremities in patients with diabetes mellitus. Prob Endocrinol. 1998;44(4):16-8.

68. Koblik T, Sieradzki J, Sendur R, et al. The effect of insulin and sulodexide (Vessel Due F) on diabetic foot syndrome: pilot study in elderly patients. J Diabetes Complicat. 2001;15(2):69-74. https://doi. org/10.1016/s1056-8727(00)00134-3.

69. Coccheri S, Scondotto G, Agnelli G, Palazzini E, Zamboni V, Arterial Arm of the Suavis (Sulodexide Arterial Venous Italian Study) Group. Sulodexide in the treatment of intermittent claudication. Results of a randomized, double-blind, multicentre, placebo-controlled study. Eur Heart J. 2002;23(13): 1057-65. https://doi.org/10.1053/euhj.2001.3033.

70. Moldovan C, Marc F, Farcaş D. Sulodexide treatment in patients with type 2 diabetes mellitus and 
intermittent claudication. Eur J Int Med. 2011;22: S63.

71. Katorkin SE. Significance of endothelial protection in treatment of patients with class c6 chronic venous disease and type 2 diabetes mellitus. Angiol Sosud Khir. 2015;21(3):99-102 (104-6).

72. Zakharova NO, Bulgakova SV, Katorkin SE, Melnikov MA, Treneva EV, Nikolaeva AV. The treatment of elderly and senile patients with venous trophic ulcers and type 2 diabetes mellitus. Adv Gerontol. 2017;30(6):917-24.

73. Solini A, Carraro A, Barzon I, Crepaldi G. Therapy with glycosaminoglycans lowers albumin excretion rate in non-insulin dependent diabetic patients with macroalbuminuria. Diabetes Nutr Metab. 1994;7(5):304-7.

74. Velussi M, Cernigoi A, Dapas F, De Monte A. Glycosaminoglycans oral therapy reduces microalbuminuria, blood fibrinogen levels and limb arteriopathy clinical signs in patients with non-insulin dependent diabetes mellitus. Diabetes Nutr Metab. 1996;9(2):53-8.

75. Dedov I, Shestakova M, Vorontzov A, Palazzini E. A randomized, controlled study of sulodexide therapy for the treatment of diabetic nephropathy. Nephrol Dial Transplant. 1997;12(11):2295-300. https://doi. org/10.1093/ndt/12.11.2295.

76. Perušičová J, Škrha J. The effect of sulodexide, a glycosaminoglycan, on albuminuria in diabetic patients. Vnitr Lek. 1997;43(11):748-52.

77. Poplawska A, Szelachowska M, Topolska J, WysockaSolowie B, Kinalska I. Effect of glycosaminoglycans on urinary albumin excretion in insulin-dependent diabetic patients with micro- or macroalbuminuria. Diabetes Res Clin Pract. 1997;38(2):109-14. https:// doi.org/10.1016/s0168-8227(97)00096-X.

78. Shestakova MV, Chugunova LA, Vorontsov AV, Dedov II. The efficacy of sulodexide-a low-molecular heparin-in the therapy of diabetic nephropathy. Ter Arkh. 1997;69(6):34-7.

79. Škrha J, Perušičová J, Pont'uch P, Okša A. Glycosaminoglycan sulodexide decreases albuminuria in diabetic patients. Diabetes Res Clin Pract. 1997;38(1):25-31. https://doi.org/10.1016/s01688227(97)00076-4.

80. Solini A, Vergnani L, Ricci F, Crepaldi G. Glycosaminoglycans delay the progression of nephropathy in NIDDM. Diabetes Care. 1997;20(5): 819-23. https://doi.org/10.2337/diacare.20.5.819.

81. Sorrenti G, Grimaldi M, Canova N, Palazzini E, Melchionda N. Glycosaminoglycans as a possible tool for micro- and macroalbuminuria in diabetic patients. A pilot study. J Int Med Res. 1997;25(2): 81-6. 030006059702500204 https://doi.org/10.1177/

82. Szelachowska M, Poplawska A, Topolska J, Kinalska I, Grimaldi M. A pilot study of the effect of the glycosaminoglycan sulodexide on microalbuminuria in type I diabetic patients. Curr Med Res Opin. 1997;13(9):539-45. https://doi.org/10.1185/ 03007999709113327.

83. Rasovskiǐ BL, Tarasov AV, Trel'skaia N, Severina TI, Chernykh EF. Sulodexide in the treatment of diabetic nephropathy. Klin Med (Mosk). 1998;76(7): $40-2$.

84. Škrha J, Perušičová J, Kvasnička J, Hilgertová J. The effect of glycosaminoglycan sulodexide on oxidative stress and fibrinolysis in diabetes mellitus. Sb Lek. 1998;99(2):103-9.

85. Zalevskaia AG, Astamirova KhS, Karpova IA, Popova SG. A trial of the use of the low-molecular heparin sulodexide in the therapy of diabetic nephropathy. Ter Arkh. 1998;70(3):71-4.

86. Oksa A, Pontuch P, Kratochvilova H. The effect of glycosaminoglycan sulodexide on albuminuria in patients with diabetes mellitus. Bratisl Lek Listy. 1999;100(9):486-9.

87. Sun M, Tian L. Clinical study on type II diabetic nephropathy treated with sulodexide. Chi J Chin New Drugs J. 1999;8:408-10.

88. Lichiardopol R, Ionescu-Tirgoviste C, Serban V, Dumitrescu C, Mota M, Ghise G. The effect of sulodexide on albuminuria in a group of patients with diabetes. Rom J Diabetes Nutr Metab Dis. $2001 ; 2: 28-31$.

89. Gambaro G, Kinalska I, Oksa A, et al. Oral sulodexide reduces albuminuria in microalbuminuric and macroalbuminuric type 1 and type 2 diabetic patients: the Di.N.A.S. randomized trial. J Am Soc Nephrol. 2002;13(6):1615-25. https://doi.org/ 10.1097/01.asn.0000014254.87188.e5.

90. Achour A, Kacem M, Dibej K, Skhiri H, Bouraoui S, El May M. One year course of oral sulodexide in the management of diabetic nephropathy. J Nephrol. $2005 ; 18(5): 568-74$.

91. Sulikowska B, Olejniczak H, Muszynska $M$, et al. Effect of sulodexide on albuminuria, NAG excretion and glomerular filtration response to dopamine in diabetic patients. Am J Nephrol. 2006;26(6):621-8. https://doi.org/10.1159/000098195.

92. Heerspink HL, Greene T, Lewis JB, et al. Effects of sulodexide in patients with type 2 diabetes and 
persistent albuminuria. Nephrol Dial Transplant. 2008;23(6):1946-54. https://doi.org/10.1093/ndt/ gfm893.

93. Blouza S, Dakhli S, Abid H, et al. Efficacy of low-dose oral sulodexide in the management of diabetic nephropathy. J Nephrol. 2010;23(4):415-24.

94. Mao L, Zhong X. Effect of sulodexide combined with benazepril on urinary albumin in patients with type 2 diabetes. Chin Mod Med. 2010;17:68-9.

95. Jian R, Jie S, Can $H$. Effect of sulodexide on microalbuminuria of the third stage of type 2 diabetic nephropathy. Mod Med J Chin. 2010;11:20.

96. Wang H. Effect of sulodexide in diabetic nephropathy. Prac J Med Pharm. 2010;27:315-6.

97. Lewis EJ, Lewis JB, Greene T, et al. Sulodexide for kidney protection in type 2 diabetes patients with microalbuminuria: a randomized controlled trial. Am J Kidney Dis. 2011;58(5):729-36. https://doi. org/10.1053/j.ajkd.2011.06.020.

98. He X, Ge Z. Curative effect of sulodexide in diabetic nephropathy patients. Clin Foc. 2012;27:1626-7.

99. Packham DK, Wolfe R, Reutens AT, et al. Sulodexide fails to demonstrate renoprotection in overt type 2 diabetic nephropathy. J Am Soc Nephrol. 2012;23(1): 123-30. https://doi.org/10.1681/ASN.2011040378.

100. Kang Z. Study on effect of sulodexide in treatment of diabetic nephropathy stage III. Guide Chin Med. 2013;11:25-8.

101. Xiong Y. Treatment of sulodexide on albuminuria in early diabetic nephropathy. J Jianghan Univ (Nat Sci Ed). 2014;42(3):90-2.

102. Satirapoj B, Kaewput W, Supasyndh O, Ruangkanchanasetr P. Effect of sulodexide on urinary biomarkers of kidney injury in normoalbuminuric type 2 diabetes: a randomized controlled trial. J Diabetes Res. 2015;2015:172038. https://doi.org/10. $1155 / 2015 / 172038$.

103. Zilişteanu DS, Atasie T, Voiculescu M. Efficacy of longterm low-dose sulodexide in diabetic and non-diabetic nephropathies. Rom J Intern Med. 2015;53(2): 161-9. https://doi.org/10.1515/rjim-2015-0022.

104. Dakhli S, Khedher A, Borni Z, Achour A, Hachicha J. A clinical experience on sulodexide in the treatment of patients with diabetic nephropathy. J Nephrol Ther. 2016;7(1):1000284. https://doi.org/ 10.4172/2161-0959.1000284.

105. Li H, Ke W, Liu J, He X Jr, Liu L, Li Y. Effect of intravenous and oral therapy with sulodexide on diabetic nephropathy. Diabetes. 2017;66:A597.
106. Pisano L, Moronesi F, Falco F, et al. The use of sulodexide in the treatment of peripheral vasculopathy accompanying metabolic diseases. Controlled study in hyperlipidemic and diabetic subjects. Thromb Res. 1986;41(1):23-31. https:// doi.org/10.1016/0049-3848(86)90276-8.

107. Piva I, Lora L, Baso A, Erle G. Controlled study of the effect of sulodexide on peripheral diabetic macroangiopathy. G Clin Med. 1985;66(1-2):37-45.

108. Arsenio L, Strata A. Hyperlipidaemias in diabetes. Therapeutic effects of a parenterally administered glucosaminoglycan: sulodexide (Vessel Due). Clin Trials J. 1987;24:312-21.

109. Szafilk J, Kamińska A. Usefulness of Vessel Due F (sulodexide) in treatment of patients with diabetic retinopathy, senile macular degeneration and retinal vein occlusion. Okulistyka. 2000;3:1-4.

110. d'Aloia A, Dati M, Della Corte M, Romano M, Lanza M, Romano A. Assessment of the effectiveness of sulodexide on diabetic patients. Boll Oculistica. 2001;80(1):37-41.

111. Karimov K, Shakhmaliyeva A. Effect of sulodexide on non-proliferative diabetic retinopathy. Azerbaijan Med J. 2002;1:72-6.

112. Li R, Xing J, Mu X, et al. Sulodexide therapy for the treatment of diabetic nephropathy, a meta-analysis and literature review. Drug Des Devel Ther. 2015;9: 6275-83. https://doi.org/10.2147/DDDT.S87973.

113. Yan W, Zhou B, Shen Y, Xu G. Antioxidant and antithrombotic therapies for diabetic kidney disease. Iran J Kidney Dis. 2015;9(6):413-20.

114. Lamblova K, Mlcoch T, Mazalova M, Dolezal T. Cost-effectiveness analysis of sulodexide in patients with non-proliferative diabetic retinopathy in the Czech Republic. Value Health. 2016;19(7):A568.

115. Tokmakova AY, Milenkaya T, Chirkova L, Arbuzova M, Antsiferov M. The use of the drug Wessel Duet F in the complex treatment of lesions of the lower extremities in patients with type II diabetes. Prob Endocrinol. 1999;45(3):14-8.

116. Klisarova A, Bihchelian H, Koeva L. Planary bone scintigraphy of the foot in the diabetics with peripheral macroangiopathy, treated with sulodexide (Vessel Due F). Rentgenol Radiol. 2000;39(4): 281-4.

117. Svetukhin AM, Zemlianoǐ AB, Orudzheva SA, et al. Experience in the use of vessel due $F$ (sulodexide) in patients with suppurative-necrotic forms of diabetic foot without critical ischemia. Ter Arkh. 2001;73(4): 31-3. 
118. Mozgovaya E, Pecherina L. Sulodexide efficacy in complex therapy and prevention of gestational toxicosis (gestosis) in patients with type 1 diabetes mellitus. Farmateka. 2006;3:128-33.

119. Olde Engberink RH, Vogt L. The renoprotective effects of sulodexide. Drug Des Devel Ther. 2016;10: 1233-4. https://doi.org/10.2147/DDDT.S102814.

120. Shustov SB. Controlled clinical trial on the efficacy and safety of oral sulodexide in patients with peripheral occlusive arterial disease. Curr Med Res Opin. 1997;13(10):573-82. https://doi.org/10.1185/ 03007999709113331.

121. Apollonio A, Antignani PL, Di Salvo M, et al. A large Italian observational multicentre study on vascular ulcers of the lower limbs (Studio Ulcere Vascolari). Int Wound J. 2016;13(1):27-34. https://doi.org/10. 1111/iwj.12216.

122. Arcangeli A, Pedone T, Crescenti C, Ianni L. Microalbuminuria and type-II diabetes: clinical efficacy of sulodexide. Preliminary data. Minerva Cardioangiol. 2000;48(11 Suppl 2):72-3.

123. Piaggesi A, Abbruzzese L, Mattaliano C, et al. Sulodexide as adjunctive therapy in diabetic foot patients with critical limb ischemia treated with percutaneous transluminal angioplasty. Int J Low Extrem Wounds. 2014;13(2):103-9. https://doi.org/ $10.1177 / 1534734614534442$.

124. Gohel MS, Taylor M, Earnshaw JJ, Heather BP, Poskitt KR, Whyman MR. Risk factors for delayed healing and recurrence of chronic venous leg ulcers-an analysis of 1324 legs. Eur J Vasc Endovasc Surg. 2005;29(1):74-7. https://doi.org/10.1016/j. ejvs.2004.10.002.

125. Coccheri S, Bignamini AA. Pharmacological adjuncts for chronic venous ulcer healing. Phlebology. 2016;31(5):366-7. https://doi.org/10.1177/ 0268355515619562 .

126. Gambaro G. Discounting the efficacy of sulodexide in diabetic nephropathy is premature. Am J Kidney Dis. 2012;60(1):169-70. https://doi.org/10.1053/j. ajkd.2012.01.029.

127. Coccheri S. Game not over for sulodexide. Am J Kidney Dis. 2012;59(3):467.

128. Rozita M, Mohd Shahrir M, Loo C, et al. Glycosaminoglycans (sulodexide) for resistant heavy proteinuria of chronic glomerulonephritides. Nephrology. 2008;13(Suppl 1):A55.

129. Kozlova L, Khokhlov R, Akhmedzhanov N. Clinical efficacy of glycosaminoglycans in patients with diabetes mellitus and ischemic heart disease. Rational Pharmacother Card. 2011;7(5):584-90.

130. Marcoux R, Larrat E, Taubman A, Wilson J. Screening for peripheral arterial disease. J Am Pharm Assoc (Wash). 1996;NS36:370-3.

131. Golomb BA, Dang TT, Criqui MH. Peripheral arterial disease: morbidity and mortality implications. Circulation. 2006;114(7):688-99. https://doi.org/ 10.1161/CIRCULATIONAHA.105.593442.

132. Heerspink HJL, Greene T, Tighiouart $H$, et al. Change in albuminuria as a surrogate endpoint for progression of kidney disease: a meta-analysis of treatment effects in randomised clinical trials. Lancet Diabetes Endocrinol. 2019;7(2):128-39. https://doi.org/10.1016/S2213-8587(18)30314-0.

133. Inker LA, Heerspink HJL, Tighiouart H, et al. GFR slope as a surrogate end point for kidney disease progression in clinical trials: a meta-analysis of treatment effects of randomized controlled trials. J Am Soc Nephrol. 2019;30(9):1735-45. https://doi. org/10.1681/ASN.2019010007.

134. Olde Engberink RH, Heerspink HJ, de Zeeuw D, Vogt L. Blood pressure-lowering effects of sulodexide depend on albuminuria severity: post hoc analysis of the sulodexide microalbuminuria and macroalbuminuria studies. Br J Clin Pharmacol. 2016;82(5): 1351-7. https://doi.org/10.1111/bcp.13062.

135. Bignamini AA, Matuška J. Sulodexide for the symptoms and signs of chronic venous disease: a systematic review and meta-analysis. Adv Ther. 2020;37(3):1013-33. https://doi.org/10.1007/ s12325-020-01232-1.

136. Gaddi A, Galetti C, Illuminati B, Nascetti S. Metaanalysis of some results of clinical trials on sulodexide therapy in peripheral occlusive arterial disease. J Int Med Res. 1996;24(5):389-406. https:// doi.org/10.1177/030006059602400501.

137. Shang H-X, Zhao J-Y, Shen X, et al. The efficacy and safety of sulodexide in patients with diabetic nephropathy: a meta-analysis of randomized controlled trials. Int J Clin Exp Med. 2016;9(7): 12481-91. 